\title{
Monsoonlike Circulations in a Zonally Averaged Numerical Model with Topography
}

\author{
V. Brahmananda Rao, J. Pablo Reyes Fernandez, and Sergio H. Franchito \\ Instituto Nacional de Pesquisas Espaciais, INPE, Sao Jose dos Campos, Brazil
}

(Manuscript received 14 May 1998, in final form 30 March 1999)

\begin{abstract}
A primitive equation global zonally averaged general circulation model is used to study the effects of the topography on the atmospheric annual cycle. A smoothed zonally averaged topography that has a form similar to that observed was used. The control experiment showed that the model was capable of capturing the zonally averaged behavior of the annual cycle. The model is able to capture some characteristics of the monsoonlike circulation such as the seasonal wind reversal and the easterly jet in the boreal summer. Even in the absence of topography the model was able to reproduce the monsoonlike features. However, the circulation was weak and the position of its components was altered. This suggests that the topography has an important role in modifying the intensity and position of the monsoon circulation. Sensitivity tests were made in order to investigate the effects of high elevation and its steep southern slope. Two experiments were performed: 1) increasing the elevation of orography without changing the steepness of the slope, and 2) increasing both the elevation and the steepness of the slope. The results indicated that the steepness of the southern slope seems to control the monsoonlike flow in the model. The model was also capable of reproducing a monsoonlike response to changed external conditions. When the values of the earth's orbital parameters (precession, obliquity, and eccentricity) were changed to those of $9000 \mathrm{yr} \mathrm{BP}$, the precipitation and circulation intensified, which seems to agree with paleoclimatic evidence.
\end{abstract}

\section{Introduction}

The annual variation of atmospheric circulation in certain parts of the Tropics is known as the monsoon. The monsoon is associated with a reversal of $180^{\circ}$ in the low-level winds from winter to summer (Fein and Stephens 1987). A large fraction of the global population living in the Asian monsoon region is affected critically by the vagaries of the monsoon. Prediction of the onset date and rainfall intensity is one of the difficult tasks of meteorologists. Skillful prediction can be made only after a clear understanding of the dynamics of a monsoon system. Regarding the basic mechanisms of a monsoon system, the shift of the wind from winter to summer due mainly to the presence of the Tibetan Plateau is believed to be the primary triggering mechanism of the monsoon onset over India (Riehl 1979). The plateau acts both as a mechanical barrier and as an elevated heat source. The mechanical barrier effect seems to be important for the winter monsoonal circulation, and the thermal effect appears to be the main mechanism for the establishment of the summer monsoon (Murakami 1987). The important role of the Tibetan Plateau in the

Corresponding author address: Dr. V. Brahmananda Rao, Instituto Nacional de Pesquisas Espasiais, INPE, CP515, 12201-970, Sao Jose dos Campos, SP, Brazil.

E-mail: vbrao@met.inpe.br development of the monsoonal circulation has been described in studies using atmospheric models. Murakami et al. (1970) noted that the inclusion of the mountain was essential for the realistic simulation of the low-level westerlies and the upper easterly jet. Das and Bedi (1981) pointed out that the plateau barrier is necessary for simulating the monsoon system and that the increase of the heating over the plateau intensifies the circulation. The numerical simulation studies of Kuo and Qian (1981, 1982) indicated that the monsoonal circulation is maintained by the sensible and latent heating and that the mechanical effects of the plateau play a modifying role. Hahn and Manabe (1975) showed that even in the absence of the Tibetan Plateau some monsoon features occur. However, the intensity of circulation is reduced. They pointed to the importance of the plateau barrier in determining the position and intensity of the various components of the monsoonal circulation. Excellent reviews of observational and modeling studies regarding the influence of the Tibetean Plateau on the monsoon are given by Meehl (1992), Murakami (1987), and Krishnamurti (1987).

An intercomparison of hydrologic processes in 29 Atmospheric Model Intercomparison Project (AMIP) models by Lau et al. (1996) showed that the models generally portray an earthlike climate. However, some models show significant errors in the total global water balance. There are other problems common to all models 
such as underestimating the frequency of the occurrence of light precipitation events $\left(<1 \mathrm{~mm} \mathrm{day}^{-1}\right)$. The simulated boreal summer rainfall distributions have large variability over the Indian subcontinent and Bay of Bengal. The northward migration of the monsoon convective zones are not well simulated. The East Asian monsoon rainband over the subtropical western Pacific is ill-defined or absent in all models. The problem was further investigated by Stephenson et al. (1998). They also discussed the failures of the models to deal with topography. Recently, a most comprehensive study on AMIP monsoon studies was made by Gadgil et al. (1998). They made a detailed comparison of monsoon precipitation in 30 AMIP models. Although the models are able to capture some of the observed characteristics of monsoon rainfall over African, Indian, and Australian-Indonesian regions, there are still quantitative differences. Whereas some models simulated the observed seasonal migration of the primary rain belt over the heated continents, in several others the rain belt remains unrealistically over the equatorial oceans in all the seasons. This is true even in the case of the rainfall pattern over the Indian region for July-August (the peak of monsoon months). The simulation of the mean summer rainfall pattern over the Indian region and its interannual variations are not well simulated in most of the models. This suggests that the three-dimensional atmospheric general circulation models (GCMs) are not yet perfect and there is need for further improvement in the simulation of several aspects of the monsoon system by these models.

An alternative to the three-dimensional GCMs is the simple models such as the zonally averaged GCMs (ZAGCMs). The advantage of these models is that the cause and effect relationship is straightforward. Further, they are highly economical unlike the GCMs. ZAGCMs can effectively be used to study the dynamics of the monsoon. Webster and Lau (1977), Webster and Chou (1980), and Webster (1983) conducted a series of experiments with ZAGCMs where the Asiatic continent and adjacent oceans were included. However, they did not take into account the effects of the topography. In these works, the monsoonal circulation was studied focusing on the heat contrast between the continent and the ocean rather than on the topography. They pointed out the important role of the interactive ocean in determining the magnitude and spatial variation of the upper-level circulation. Although these studies provide some useful information, they should be extended in order to investigate the effect of orography on the monsoonal circulation.

In addition, ZAGCMs can also be used to test the sensitivity of monsoonal circulation for some of the external conditions. Monsoon strength underwent major changes during the glacial maximum at $18000 \mathrm{yr} \mathrm{BP}$ and subsequent to it. The monsoon was weak during and after the glacial maximum, and between 10000 and 5000 yr BP monsoon rains got reestablished (Kutzbach and Gallimore 1988; Kutzbach and Guetter 1986; De Noblet et al. 1996). The earth's orbital parameters during the Early Holocene might have influenced the climate through their effects on the seasonal cycle of radiation.

In the present study, we use a ZAGCM with topography for simulating the zonally averaged annual cycle. Since monsoonal circulations are the annual variations in certain parts of the Tropics, we attempt to investigate the capability of the ZAGCM to capture seasonal monsoonlike variations. Special emphasis is given to the impact of orography on the monsoonlike flow. Another objective of the paper is to verify if the model responds to changed external condition such as those during the Early Holocene (9000 BP). One must keep in mind that the model is designed to calculate zonal means and not exactly the regional features such as the actual Asian monsoon. However, since the monsoon is a response to the annual cycle, the capability of the model in capturing some monsoonlike variations (hereafter referred to as simply monsoon) will be investigated. For this purpose, we use a smoothed zonally averaged topography in the ZAGCM (section 2f), which is different from the actual Himalayan-Tibetan plateau. To our knowledge, the topographic effect was not taken into account in the earlier ZAGCMs. Section 2 contains the model description, the simulation of the annual cycle, and the monsoon circulation. The effects of the topography on the monsoon features are presented in section 3. Section 4 contains the results of the Holocene experiment. The summary and conclusions are given in section 5 .

\section{The model}

The ZAGCM used in the present study is similar to that developed by Franchito and Rao (1992). The model is essentially mechanistic and has been utilized extensively to study various aspects of climate and climatic change (Franchito and Rao 1992, 1995; Rao and Franchito 1993; Varejão-Silva et al. 1998; Franchito et al. 1998). It is a two-layer global primitive equation model in sigma coordinate and includes parameterizations of friction, diabatic heating, and large-scale eddies. The fraction of the latitude belt covered by each type of surface is obtained from Saltzman and Vernekar (1972). The surface albedo and the surface water availability are obtained through the weighted mean of these specific values using as weight the fraction of the latitude belt covered by each type of surface.

In the present study, several improvements have been made. The model resolution is increased and the diabatic heating parameterizations are modified in order to take into account physical processes that were not considered in the earlier version of the model. The present version includes a parameterization of the daily solar radiation and an explicit equation for the water vapor. The formulations of the sensible and latent heat fluxes are changed in order to include the effect of air temperature near the surface. The parameterizations of cumulus con- 
TABLE 1. Formulations of the surface and atmospheric fluxes.

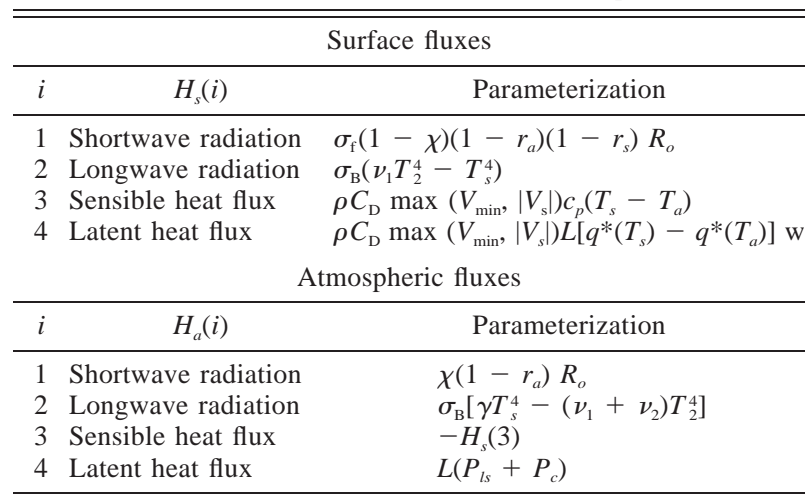

vection and large-scale precipitation are also incorporated in the model. Because of the different heat storage characteristics, continental and oceanic temperatures go through different annual cycles. So, in the present version of the model the surface energy budget at each latitude belt is computed separately for each portion of land, ocean, and snow/ice. The energy budget in the entire latitude belt is obtained through the weighted mean of the surface energy budget at each portion using as weight the fractions of land, ocean, and snow/ice in the latitude belt. Another improvement is the inclusion of the topography. The model modifications are indicated below.

\section{a. Equation of the moisture conservation}

The present model includes an explicit water vapor equation (Haltiner and Williams 1980):

$$
\partial p_{s} q_{3} / \partial t=-\nabla\left(p_{s} v_{3} q_{3}\right)+p_{s} S
$$

where $v_{3}$ and $q_{3}$ are the meridional wind and the specific humidity at $750 \mathrm{hPa}$, respectively; ps is the surface pressure; and $S$ is given by the difference between the evaporation and condensation:

$$
S=g(E-P) /\left[p_{s}(\delta \sigma)_{3}\right] .
$$

In expression (2), $(\delta \sigma)_{3}$ corresponds to $\Delta \sigma$ in the lower model layer.

\section{b. Solar radiation flux}

The formulation of the solar radiation flux is similar to that used by Franchito and Rao (1992) (Table 1). However, in the earlier version of the model, the value of $R_{0}$ corresponded to the mean annual solar radiation flux at the top of the atmosphere. In the present model, the effect of the daily solar radiation flux is taken into account. So, $R_{0}$ is given by

$$
R_{0}=S \cos Z \gamma,
$$

where $S$ is the solar constant, and $Z$ is the zenith angle calculated using the expression:

$$
\cos Z=H \sin \varphi \sin \delta+\cos \varphi \cos \delta \cos H,
$$

where $\varphi, \delta$, and $H$ are the latitude, the solar declination, and the hour angle, respectively. The astronomical parameters necessary for the calculation of the zenith angle are obtained following the procedure given by Berger (1978).

\section{c. Sensible and latent heat fluxes}

In the original version of the model, the formulation of the sensible $\left[H_{s}(3)\right]$ and latent $\left[H_{s}(4)\right]$ heat fluxes were the same as those proposed by Saltzman and Vernekar (1971). In the present model, however, we use the bulk parameterization of these fluxes (Haltiner and Williams 1980; Held and Suarez 1978):

$$
\begin{aligned}
& H_{s}(3)=\rho C_{D} \max \left(V_{\min },\left|V_{s}\right|\right) c_{p}\left(T_{s}-T_{a}\right), \\
& H_{s}(4)=\rho C_{D} \max \left(V_{\min },\left|V_{s}\right|\right) L\left[q^{*}\left(T_{s}\right)-q^{*}\left(T_{a}\right)\right] w,
\end{aligned}
$$

where $\rho$ is the air surface density $\left(1.25 \mathrm{~kg} \mathrm{~m}^{-3}\right) ; C_{D}$, the drag coefficent $\left(1 \times 10^{-3}\right.$ over land, and $3 \times 10^{-3}$ over ocean); $w$, the water availability at surface; $V_{s}$, the surface wind; $V_{\min }=1.5 \mathrm{~m} \mathrm{~s}^{-1} ; T_{s}$ and $T_{a}$, the surface and air surface temperatures; and $q^{*}\left(T_{s}\right)$ and $q^{*}\left(T_{a}\right)$, the saturation specific humidity at temperatures $T_{s}$ and $T_{a}$, respectively. Also, $H_{s}(4)=\mathrm{LE}$. The surface air temperature is obtained following the procedure used by Held and Suarez (1978):

$$
T_{a}=\nu T_{1}+(1-\nu) T_{3},
$$

where

$$
\nu=\left(\ln p_{s}-\ln p_{1}\right) /\left(\ln p_{3}-\ln p_{1}\right) .
$$

In expressions (7) and (8), $T_{1}$ and $T_{3}$ are the temperatures at the levels $\sigma=0.25$ and $\sigma=0.75$, respectively, and $p_{1}$ and $p_{3}$ are the pressures at these levels.

\section{d. The energy balance at the surface}

Since we are taking into account the daily values of $R_{0}$ (and not the diurnal cycle of $R_{0}$ ), the effect of the subsurface heat flux is neglected in the model $\left[H_{s}(5)=\right.$ $0]$. Assuming that the surface has zero heat capacity, the energy balance at the surface is given by

$$
\sum H_{s}(i)=0, \quad i=1,2,3,4,
$$

where the surface energy fluxes $H_{s}(i)$ are given in Table 1. This assumption may have implications for the monsoon flow simulation. The observed delay in land surface warming of continent is about 1-2 months and this is important for monsoon circulations. Therefore, the zero heat capacity model may provoke an earlier onset of monsoon.

The land surface temperature is calculated applying expression (9) to the fraction of land in the latitude belt. In the case of the portions of ocean and snow/ice, we 
assumed that the surface temperatures are constant and equal to the hydrosphere temperature $\left(T_{\mathrm{DH}}\right)$ and the lithosphere temperature $\left(T_{\mathrm{DL}}\right)$, respectively, whose values are given by Saltzman and Vernekar (1972). The surface energy budget in the entire latitude belt is computed through the weighted-mean of the values of the fluxes at each portion using as weight the fractions of land, ocean, and snow/ice in the latitude belt.

\section{e. Cumulus convection and large-scale precipitation}

In the original model, the formulation of the condensation $\left[H_{a}(4)\right]$ was similar to that proposed by Gutman et al. (1984): for the latitudes near the poles the precipitation was dependent on the evaporation and a correction factor that was related to the difference between the cloudiness amount in a latitude belt and its hemispheric average; for the other latitudes, the precipitation was given by the sum of the evaporation and a factor proportional to the vertical velocity, which represented the convergence of the water vapor flux. In the present model, we introduce the parameterizations of the cumulus convection and the large-scale precipitation. We take into account these effects using the formulation of the convective adjustment described in Held and Suarez (1978).

This technique is based on the vertical temperature and specific humidity profiles. The convective adjustment is needed in superadiabatic lapse rate and/or supersaturation conditions. At the level of $\sigma=0.25$, the water vapor content is negligible. Defining the relative humidity at $\sigma=0.75$ as $r=q_{3} / q_{3}^{*}$, where $q_{3}^{*}$ is the saturation specific humidity at this level, precipitation occurs whenever $r$ is larger than a threshold value (0.8). For the unsaturated case $(r<0.8)$, if the lapse rate is larger than the dry-diabatic lapse rate $\left(\gamma>\gamma_{\mathrm{d}}\right)$ (unstable case) the vertical temperature profile is adjusted to a neutral (or slightly stable) lapse rate $\left(\gamma=\gamma_{d}=g / c_{p}\right)$ and the vertical specific humidity profile is unchanged $\left(\delta q_{3}=0 ; \delta T \neq 0\right)$. This procedure is called "dry convective adjustment."

For the saturated case $(r \geq 0.8)$, large-scale precipitation occurs when the lapse rate is smaller than the moist-adiabatic lapse rate $\left(\gamma<\gamma_{m}\right)$ (stable case), and the temperature and specific humidity vertical profiles are adjusted as given below:

$$
\begin{aligned}
& \qquad \begin{aligned}
\delta q_{3} & =\left(q_{3}-q_{\max }\right) /\left[1+\left(L / c_{p} \partial q_{\max } / \partial T\right)\right], \\
\delta T_{3} & =L / c_{p} \delta q_{3},
\end{aligned} \\
& \text { here } q_{\max }=0.8 q_{3}^{*} . \\
& \text { The large-scale precipitation is given by } \\
& \qquad P_{\mathrm{ls}}=p_{s} / 2 g \delta q_{3} .
\end{aligned}
$$$$
\text { where } q_{\max }=0.8 q_{3}^{*} \text {. }
$$

After the vertical profiles of temperature and specific humidity are adjusted, the lapse rate is again checked. If the $T$-profile is stable, no further adjustment is made, and if it is unstable the entire process is repeated.

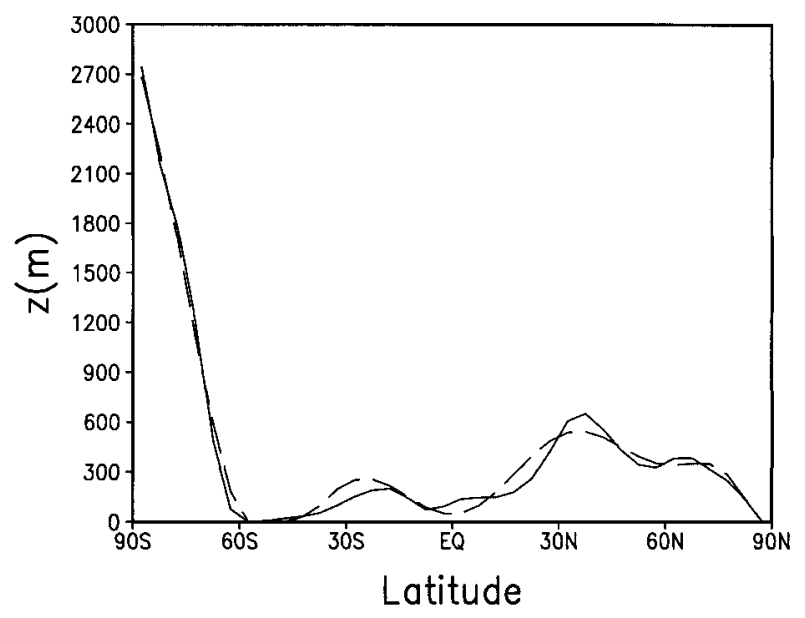

FIG. 1. Zonally averaged topography (m): observed (Tang 1976; full line) and smoothed values used in the model (dashed line).

When $\gamma \geq \gamma_{m}$ (unstable conditions) and $r \geq 0.8$ (saturated case), the convective precipitation (small-scale precipitation) takes place and both the specific humidity and temperature vertical profiles are adjusted. The first one is adjusted according to the expression (10), while the latter is adjusted to a moist neutral lapse rate $(\gamma=$ $\left.\gamma_{m}\right)$.

\section{f. The inclusion of topography in the model}

In the present paper, we take into account the effects of topography in the ZAGCM. The model topography is based on the observed zonally averaged values given by Tang (1976). To avoid excessive precipitation (due to excessive ascending motion) in the Northern Hemisphere tropical region, a smoothed zonally averaged topography, which has a form similar to that observed, is used in the ZAGCM (Fig. 1). This is obtained using the least-squares method with $10^{\circ}$ of freedom. So, the effect of topography in the zonally averaged climate can be studied at least in a preliminary way.

\section{g. Model resolution and initial conditions}

In the earlier works with this model, the meridional grid interval was $10^{\circ}$. To verify the effect of meridional resolution on results, the model has been tested against observations with a grid spacing of $10^{\circ}, 5^{\circ}$, and $2.5^{\circ}$. It has been found that the results improved with $5^{\circ}$ resolution compared to those of $10^{\circ}$ and there are no major differences between $5^{\circ}$ and $2.5^{\circ}$. Since the computation time is less for $5^{\circ}$, for the present study $5^{\circ}$ resolution has been adopted.

The initial conditions for the time integration are: an isothermal atmosphere $(270 \mathrm{~K})$ and a state of no motion. The latitudinal centered finite-difference scheme is employed. The model equations are time integrated using an explicit scheme. To obtain stability in the integration, 


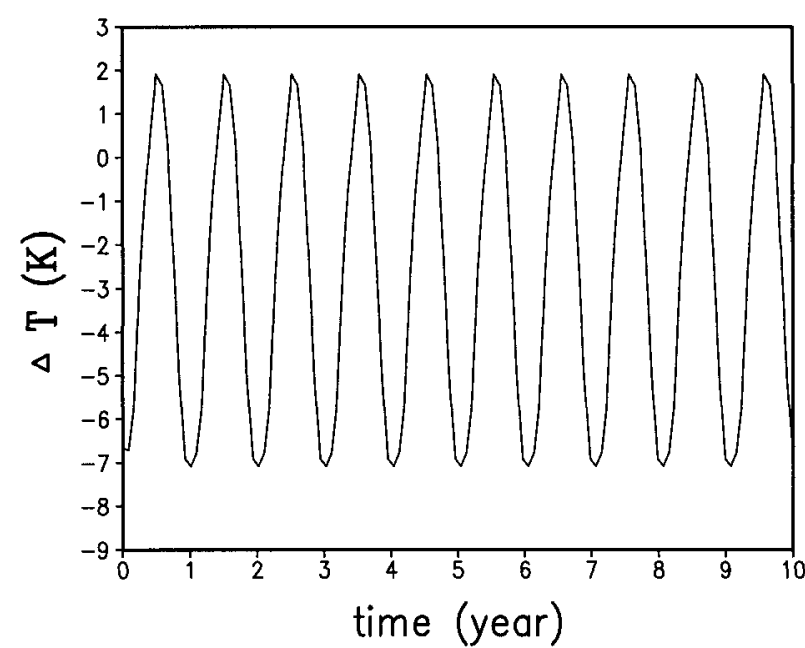

FIG. 2. Difference between the simulated zonally averaged surface temperature at $20^{\circ} \mathrm{N}$ and at the equator for $10 \mathrm{yr}$ of model integration. Units, K.

the Brown and Campana scheme (1978) and Asselin filter are used. The model is integrated for $10 \mathrm{yr}$ using daily values of the solar radiation. It converges to steady annual cycle in $1 \mathrm{yr}$. There is no interannual variation (see Fig. 2) because the seasonal values of the surface temperature in the ocean and snow/ice parts of a latitude belt are the same in all the years of integration. The results reported here are for the third year.

\section{Simulation of the annual cycle and monsoon circulation, and the effects of the zonally averaged topography on the monsoonlike features}

What characterizes monsoon is the annual variation. The monsoon is associated with a reversal of $180^{\circ}$ in the low-level winds from winter to summer (Fein and Stephens 1987). To verify the ability of the ZAGCM to capture some seasonal monsoonlike variations, the model is run to simulate the annual cycle of the zonally averaged atmosphere. For this purpose, the ZAGCM is run using the present-day daily values of the solar radiation at the top of the atmosphere. First, the simulated characteristics of the annual cycle and monsoonlike circulation are shown. In the second part of this section, the results concerning the effects of zonally averaged topography on the monsoon circulation are presented. We will show the model results for the latitudinal domain $50^{\circ} \mathrm{S}-50^{\circ} \mathrm{N}$ because in the present study we are focusing on the tropical latitudes. As mentioned in the introduction, the model results refer to the zonal-mean general circulation behavior rather than the behavior in the Asian sector. Also, the topography used in the model is a smoothed zonally averaged topography, which is different from the Himalayan-Tibetan plateau. It must be kept in mind that the ZAGCM is a mechanistic model. Our objective is to investigate the capability of this

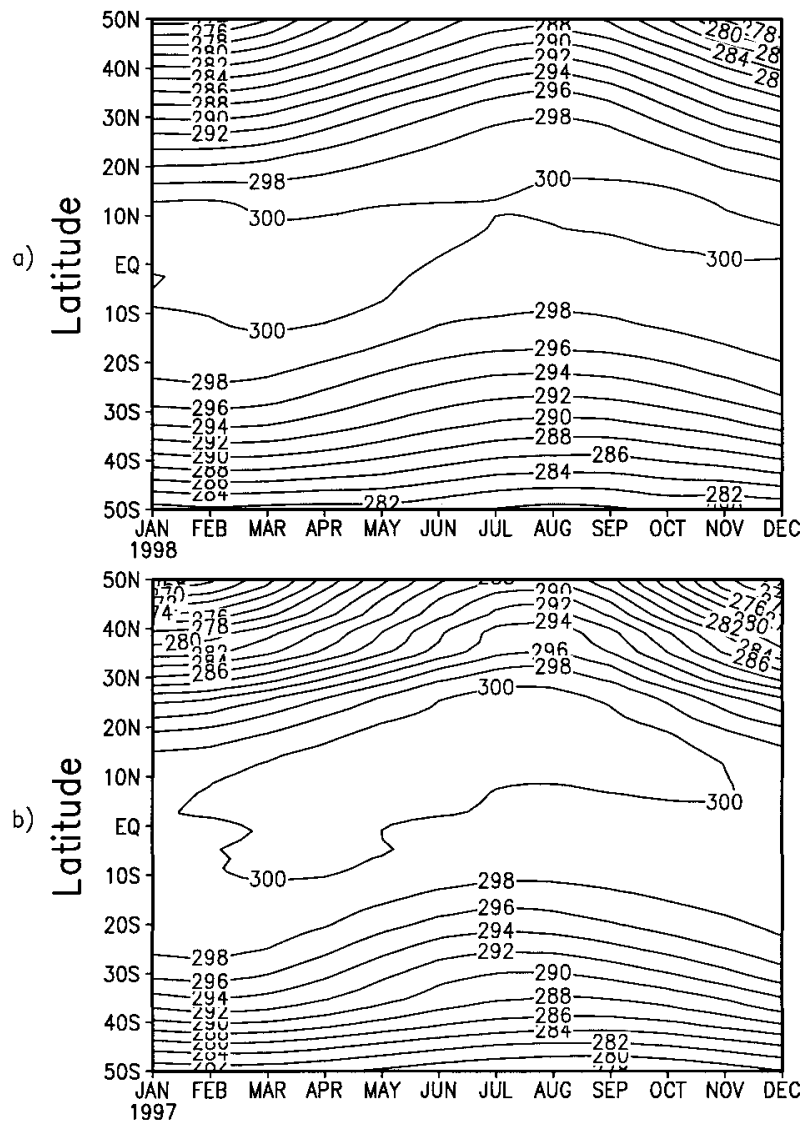

FIG. 3. Annual variation of the zonally averaged surface temperature (K). Interval $2 \mathrm{~K}$ : (a) model, and (b) observations (NCEPNCAR reanalysis data).

simple model to capture seasonal monsoonlike variations rather than to simulate the regional features of the observed Asian monsoon system. Thus, some quantitative differences between the model simulations and the observations are expected. The observed data used in this section are obtained from the National Centers for Environmental Prediction-National Center for Atmospheric Research (NCEP-NCAR) reanalysis data (mean values for 1968-96). Details regarding these data are given by Kalnay et al. (1996).

\section{a. Simulation of the annual cycle and monsoonlike circulation}

In this section the simulated zonally averaged annual cycle is compared with the observations. We will attempt to investigate the ability of the model to capture monsoon variations. Figures $3 a$, b show the annual variation of surface temperature (mean land-sea surface temperature) as simulated by the model and in observations, respectively. As can be seen, the maxima are reasonably well simulated. Note that in the model the maximum occurs about a month earlier compared to observations. This may due to the zero soil heat capacity 

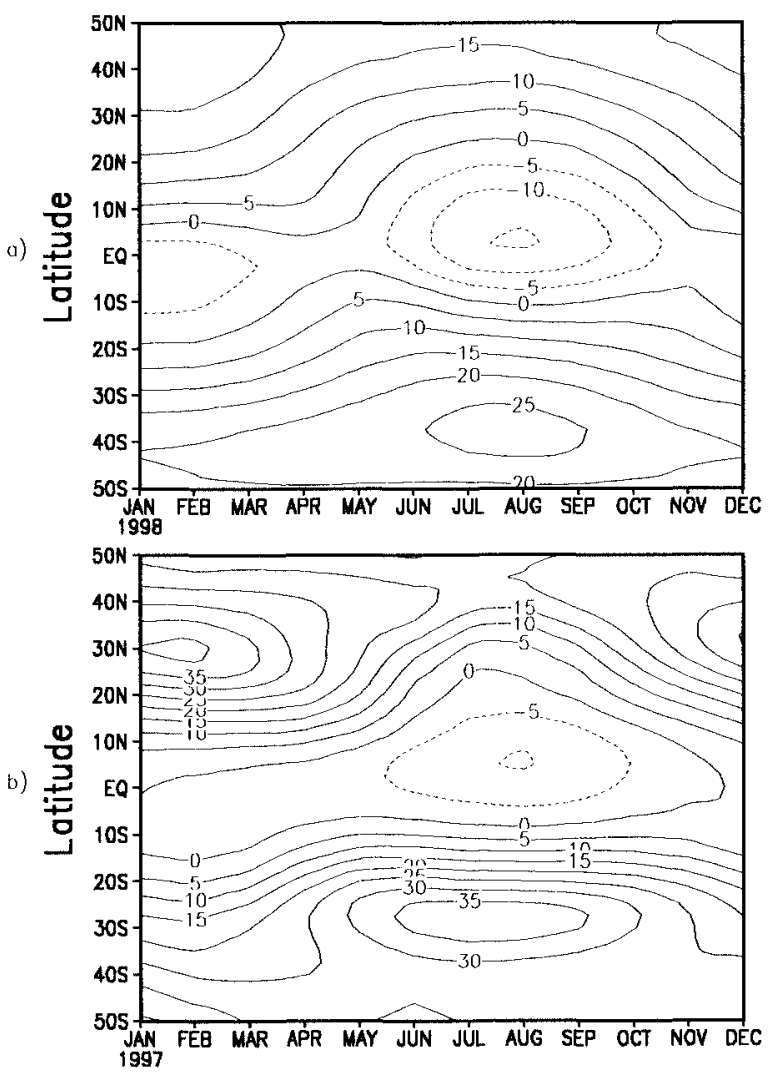

c)
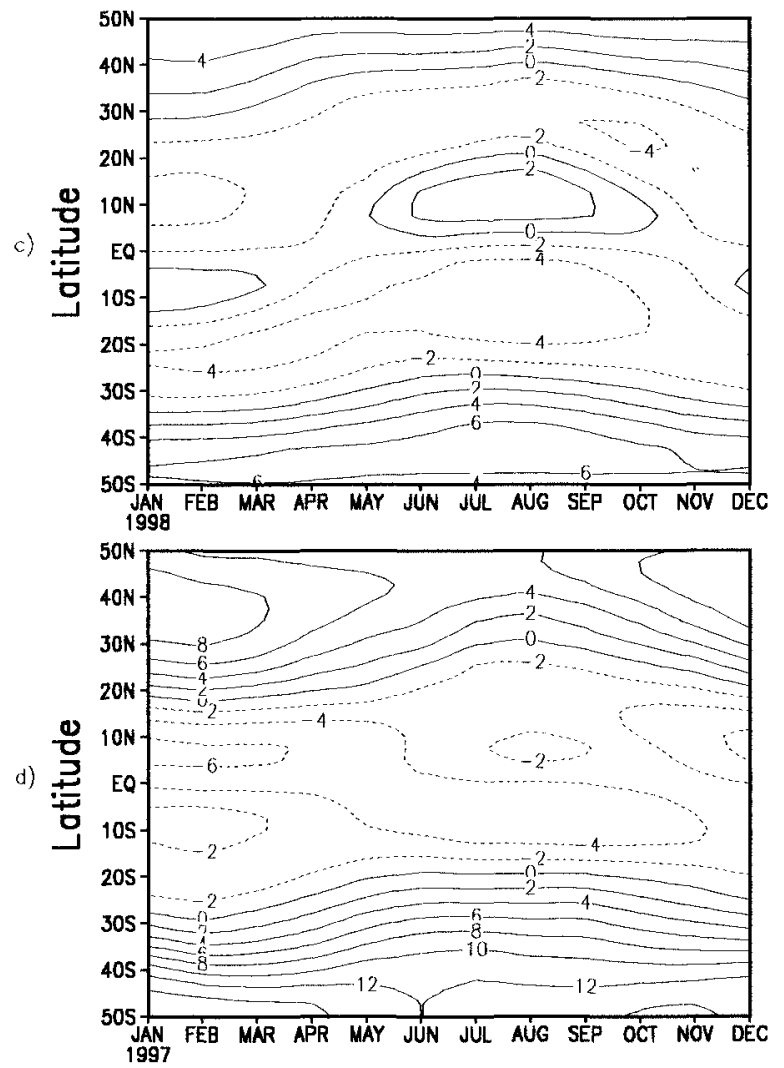

FIG. 4. Annual variation of the zonally averaged zonal wind at $250 \mathrm{hPa}$ : (a) model and (b) observations (Interval $5 \mathrm{~m} \mathrm{~s}{ }^{-1}$ ), and at 750 hPa: (c) model and (d) observations (interval $2 \mathrm{~m} \mathrm{~s}^{-1}$ ). The observed values are obtained from the NCEP-NCAR reanalysis data.

assumed in this study. This maximum is located in the region where the summer monsoon develops.

Figures $4 \mathrm{a}, \mathrm{b}$ show the simulated and observed annual variation of the zonally averaged zonal wind at $250 \mathrm{hPa}$. As can be seen, there is a qualitative good agreement between the simulation and observations. The positions of the maxima of the zonal wind at $250 \mathrm{hPa}$ are well simulated in both the hemispheres although the magnitudes are lower in the simulation than in the observed values. It is also seen that the region of easterlies near the equator is well simulated, but in the model results, the winds are stronger than observations forming an easterly jet. The occurrence of an upper-level easterly jet is one of basic characteristics of monsoon circulation. Figures $4 \mathrm{c}$,d show the simulated and observed annual variation of the zonally averaged zonal wind at $750 \mathrm{hPa}$. The region of the maxima are well simulated in both the hemispheres although their magnitudes are again underestimated. Also, the model results show the presence of low-level westerlies in the Northern Hemisphere tropical region during the boreal summer. This is another observed characteristic of monsoon circulation.

The simulated annual cycle of the zonally averaged meridional wind at $250 \mathrm{hPa}$ is in good agreement with the observations, as can be seen in Figs. 5a,b. Although the regions of northerlies and southerlies at $750 \mathrm{hPa}$ are simulated reasonably well, the magnitude of the winds is overestimated (Figs. 5c,d). This is due to the fact that in the present model the meridional winds at $750 \mathrm{hPa}$ have approximately the same magnitude but opposite sign as those of the meridional winds at $250 \mathrm{hPa}$. As can be noted in Fig. 5, the model seems to be capable of capturing another characteristic of monsoon circulation: the presence of upper-level northerlies and lowlevel southerlies in the Northern Hemisphere tropical region during the boreal summer.

Figure 6 shows the annual cycle of the zonally averaged vertical velocity $(\varpi)$ at $500 \mathrm{hPa}$ and the precipitation. The simulated values agree qualitatively well with the observations. The Hadley cell is stronger in winter hemisphere and the regions of rising motion and subsidence are well reproduced by the model. The seasonal variation of the precipitation shows a low-latitude maxima occurring during the boreal summer as in the observations. Thus, the model reproduces another monsoon feature, that is, the occurrence of strong rising motion and heavy rainfall associated with the convection in the tropical region during the boreal summer.

Vertical shear is strongly related to monsoon flow. Webster and Yang (1992) proposed that the zonal wind shear, $U$-index $\left(U_{850}-U_{200}\right.$, averaged over $40^{\circ}-110^{\circ} \mathrm{E}$, equator $-20^{\circ} \mathrm{N}$ ), provides a good index for the large-scale 

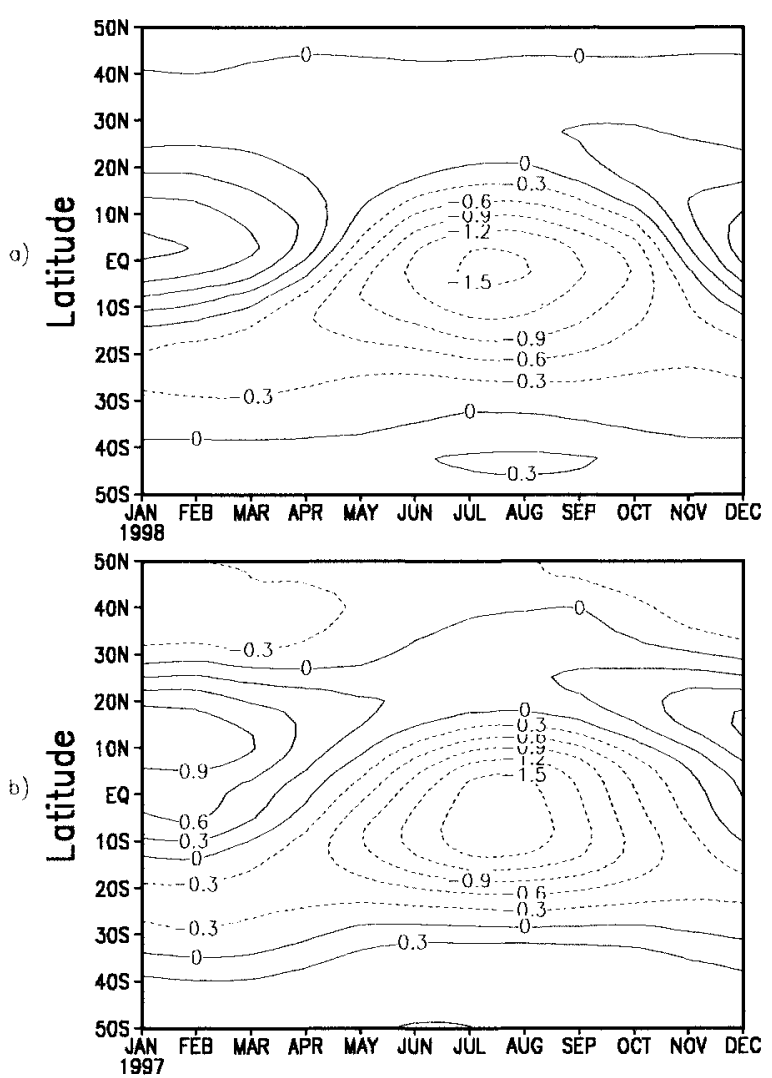

c)
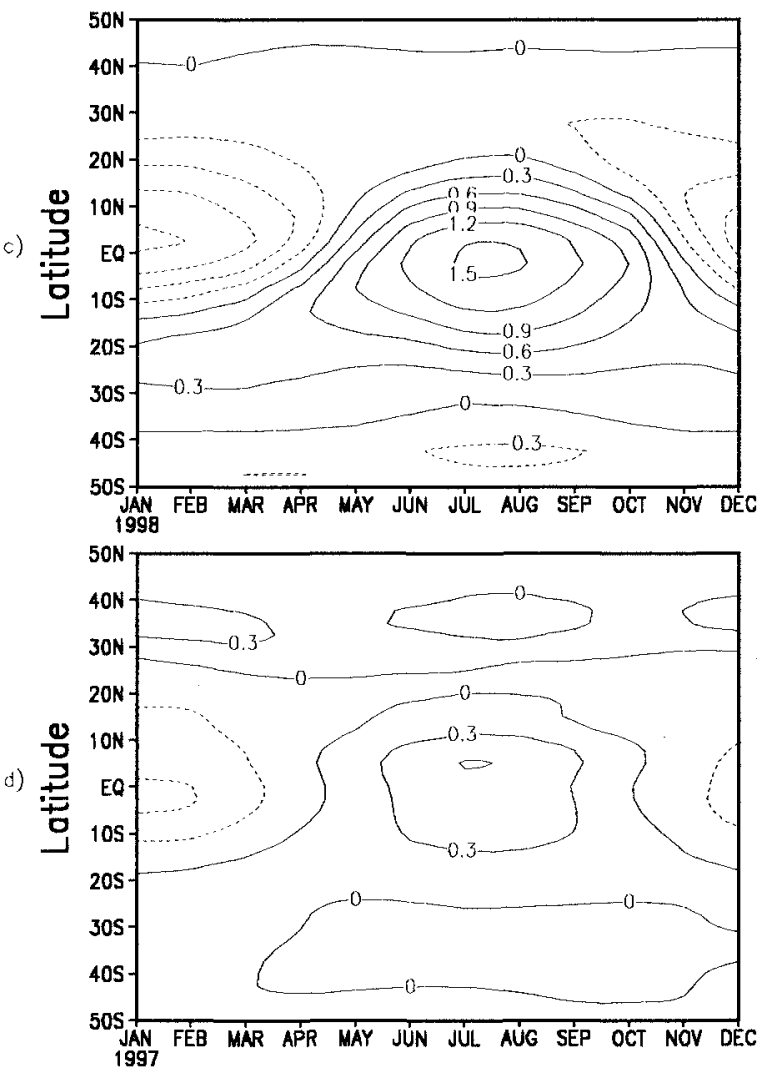

FIG. 5. Annual variation of the zonally averaged meridional wind at $250 \mathrm{hPa}$, (a) model and (b) observations, and at 750 hPa, (c) model and $(\mathrm{d})$ observations (interval $0.3 \mathrm{~m} \mathrm{~s}^{-1}$ ). The observed values are obtained from the NCEP-NCAR reanalysis data.

monsoon circulation. Taking into account that the zonal wind shear index may dectect equatorial longitudinal circulation rather than the local Hadley circulation related to the Asian monsoon, Goswami et al. (1997, manuscript submitted to Quart J. Roy. Meteor. Soc.) proposed the use of the meridional wind shear index, $V$-in$\operatorname{dex}\left(V_{850}-V_{200}\right.$, averaged over $70^{\circ}-110^{\circ} \mathrm{E}$, equator$30^{\circ} \mathrm{N}$ ). To investigate the relation between the zonally averaged vertical wind shear and the monsoon circulation simulated by the model, Fig. 7 is prepared. In the present study, the zonally averaged $U$ - and $V$-indices are given by the differences between the winds at the model levels $250 \mathrm{hPa}$ and $750 \mathrm{hPa}$. As can be seen in Figs. $7 \mathrm{a}-\mathrm{d}$, the annual cycles of the $U$ - and $V$-indices are qualitatively in agreement with the observations. However, the $U$-index is underestimated in the winter hemisphere around $30^{\circ} \mathrm{N}(\mathrm{S})$ and overestimated in the tropical region during the boreal summer, while the $V$-index is stronger than the observations at almost all latitudes. This is in agreement with the simulated annual cycles of the $u$ - and $v$-winds shown in Figs. 4 and 5, respectively. It can be noted from Fig. 7 that the simulated values of the $U$ - and $V$-indices are stronger than the observations in the Northern Hemisphere tropical region during the boreal summer. This suggests that the model overestimates the strength of monsoon circula- tion, in agreement with the excessive precipitation rates shown in Fig. 6.

The results presented above show that the simulated zonally averaged annual cycle is in a reasonably good agreement with the observations. The results also indicated that the model is able to capture some characteristics of monsoon circulations. As mentioned earlier, in the regions affected by the monsoon regime there is a reversal of the low-level wind from winter to summer. Although the present model is a zonally averaged model we will now investigate how well it is capable of capturing this regional feature. For this purpose, Fig. 8 is prepared. This figure shows the streamlines at $925 \mathrm{hPa}$ and $250 \mathrm{hPa}$ in the simulation and in the observations. The observations are obtained from the NCEP-NCAR reanalysis data along $80^{\circ} \mathrm{E}$, which strongly represent the monsoon. The model winds at $925 \mathrm{hPa}$ are obtained by logarithmic interpolation. Taking into account the simplicity of the model, the simulation of the southwest and northeast monsoonlike flow should be considered excellent. As can be seen in Figs. 8a,b, in the boreal summer the low-level southeasterly winds diverge out of the Southern Hemisphere subtropical high becoming southwesterly winds as they cross the equator. Also, as noted earlier, the upper-tropospheric easterly jet in the summer season is well simulated (Figs. 8c,d). Thus, 

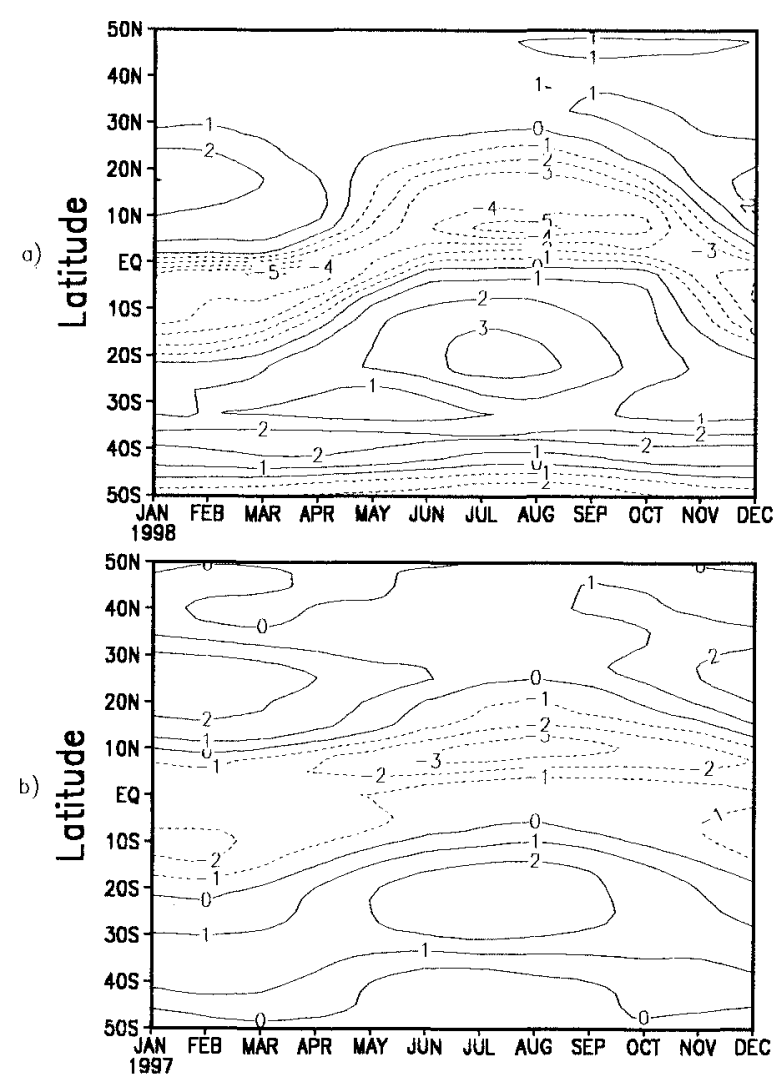
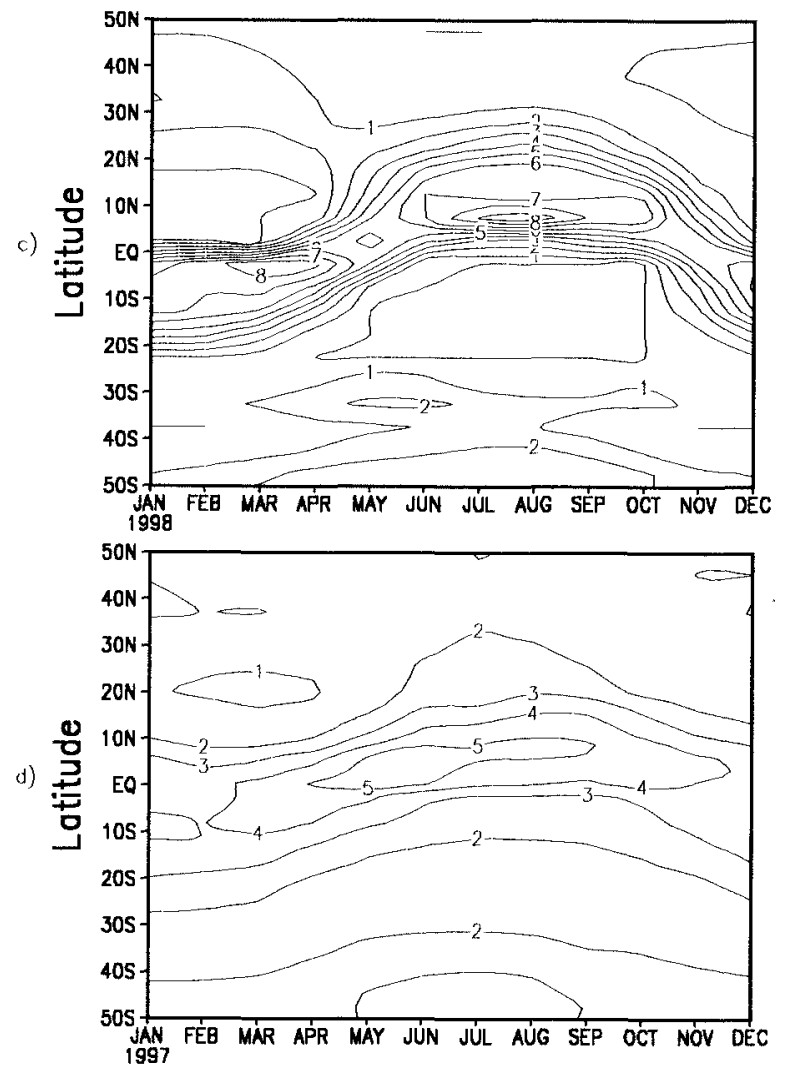

FIG. 6. Annual variation of the zonally averaged vertical velocity $\varpi$ at $500 \mathrm{hPa}\left(10^{-4} \mathrm{hPa} \mathrm{s} \mathrm{s}^{-1}\right)$ : (a) model and (b) observations, and the precipitation $\left(\mathrm{mm} \mathrm{day}^{-1}\right)$ : (c) model and (d) observations. The observed values are obtained from the NCEP-NCAR reanalysis data.

these basic features of the monsoon system are captured by the present model. The reason for the differences between the complex picture at the middle and high latitudes of the Northern Hemisphere in the NCEPNCAR data and the model results may be attributed to the fact that the data correspond to values of the wind along $80^{\circ} \mathrm{E}$ and the simulations refer to zonally averaged values. Also, the NCEP-NCAR data are influenced by the observed three-dimensional topography and the model takes into account only a smoothed zonally averaged topography.

The preceding section illustrates that the present ZAGCM is capable of capturing some basic features of a monsoon circulation. Because the simulations are based on a simple 2D model, it is not expected that the model would exactly reproduce the observed features of the actual monsoon.

\section{b. Effects of the zonally averaged topography on the monsoonlike circulation}

To investigate the effects of zonally averaged topography on the monsoon circulation we will compare the annual cycle simulated by the model with and without topography. The results show that the rising motion in the tropical region during the boreal summer is weak- ened when the topographic effects are not taken into account in the model (see Figs. 9a and 6a). As a consequence of the decrease of the rising motion, there is a decrease of the precipitation when a flat surface is considered. The topography influences both the intensification and the position of the tropical convective zone. As can be inferred from Fig. 9b, Fig. 6c (case with topography), and Fig. 6d (observations), the seasonal migration of the tropical convective zone is better represented when the topography is included in the model. As mentioned in the introduction, some of the GCMs have difficulty in reproducing this effect.

Figures 10a,b show the streamlines at $250 \mathrm{hPa}$ and $925 \mathrm{hPa}$, respectively, for the case without topography. It can be seen that even in the absence of the topography the principal features of the monsoon circulation such as the seasonal wind reversal and the upper-tropospheric easterly jet are captured by the model. However, in the case of no topography the subtropical jet does not abruptly jump northward to its summertime position as observed (Lau and Yang 1996), but it slowly moves northward throughout May and June. When the topography is included, the model reproduces reasonably well the rapid northward jump of the westerly jet across the mountain during the monsoon onset, and the establishment of the upper-tropospheric easterly jet and the low- 

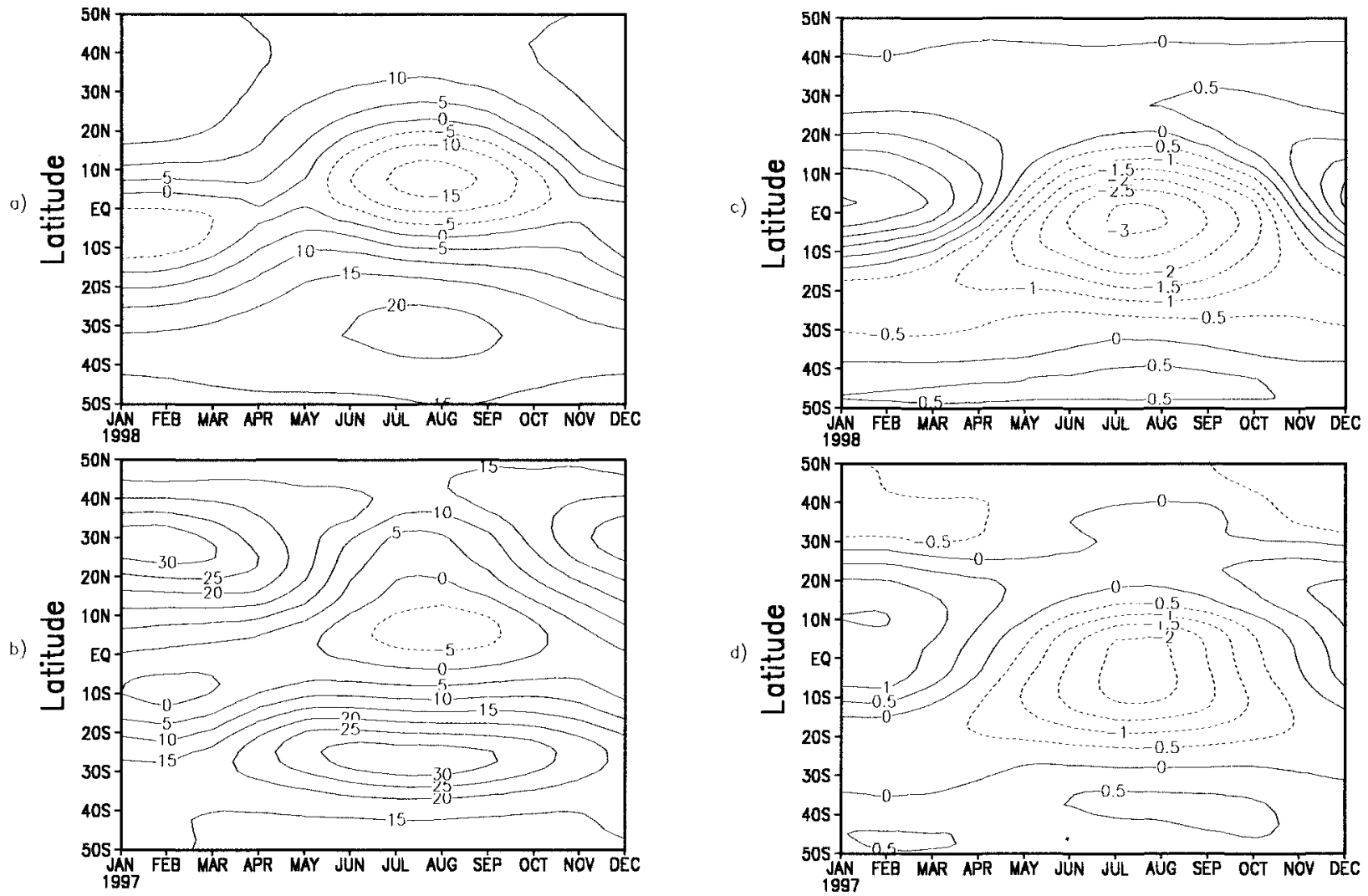

FIG. 7. Annual variation of the zonally averaged: $U$-index $\left(U_{250}-U_{750}\right)$ simulated by the model (a), and observed (b), and $V$-index $\left(V_{250}\right.$ $\left.-V_{750}\right)$ simulated by the model (c) and observed (d). The observed values are obtained from the NCEP-NCAR reanalysis data.

level westerlies to the south of the mountain (Fig. 8). To further illustrate the mountain effect Figs. 11a,b are prepared. Figures 11a,b show the horizontal wind vectors at $750 \mathrm{hPa}$ for the cases with and without mountain, respectively. Both the figures show the onset of summer monsoon in the beginning of boreal summer. However, there are several important differences between the two cases. A careful comparison of the figures shows that in the case without mountain the change at $5^{\circ} \mathrm{N}$ from northeasterlies to southwesterlies occurs around 20 May. This change gradually penetrates to $15^{\circ} \mathrm{N}$ by about the beginning of July, whereas in the case with mountain the change at $5^{\circ} \mathrm{N}$ occurs in the beginning of May and at $15^{\circ} \mathrm{N}$ it occurs in the beginning of June. In this case with mountain the southwesterly monsoonal circulation penetrates to even $20^{\circ} \mathrm{N}$, which did not happen in the case without mountain. At $20^{\circ} \mathrm{N}$ in the mountain case the westerlies continue up to about the end of August and then change to easterlies. Thus, in the case with mountain the summer monsoonlike circulation occurs rather suddenly and penetrates farther north. These features are reminiscent of the southwest monsoonal circulation in the real atmosphere and show the important role of the mountain in the realistic simulation of monsoon circulations. This agrees with results from studies using GCMs (Hahn and Manabe 1975) and observations (Yin 1949; Lau and Yang 1996).

Figures 12a,b show, respectively, the 3-month means of the zonally averaged zonal and meridional winds velocity at $250 \mathrm{hPa}$ and $750 \mathrm{hPa}$ for June-August (JJA). The period JJA will be called as summer season. As can be seen in Fig. 12a, the presence of the topography intensifies the summer monsoon circulation. Without mountain, the maxima in low-level westerlies and the upper easterly jet are around $2.4 \mathrm{~m} \mathrm{~s}^{-1}$ and $9.3 \mathrm{~m} \mathrm{~s}^{-1}$, respectively. When the mountain is included, these values increased to $3.0 \mathrm{~m} \mathrm{~s}^{-1}$ and $12.7 \mathrm{~m} \mathrm{~s}^{-1}$, respectively. This is in agreement with GCM results obtained by Murakami et al. (1970), although in the latter the magnitude of the changes was larger. It can be also seen in Fig. 12a that the position of the upper easterly jet is shifted $5^{\circ}$ northward when the topography is included in the model. It can be noted in Fig. $12 \mathrm{~b}$ that the lowlevel southerlies in JJA are stronger in the southern slope of the mountain compared to the case of no mountain. The presence of strong low-level southerlies and upper northerlies to the south of the Tibetan Plateau was noted by Kuo and Qian (1981) and agrees with observations (see Murakami 1987).

Figures $13 \mathrm{a}, \mathrm{b}$ show the zonally averaged total pre- 

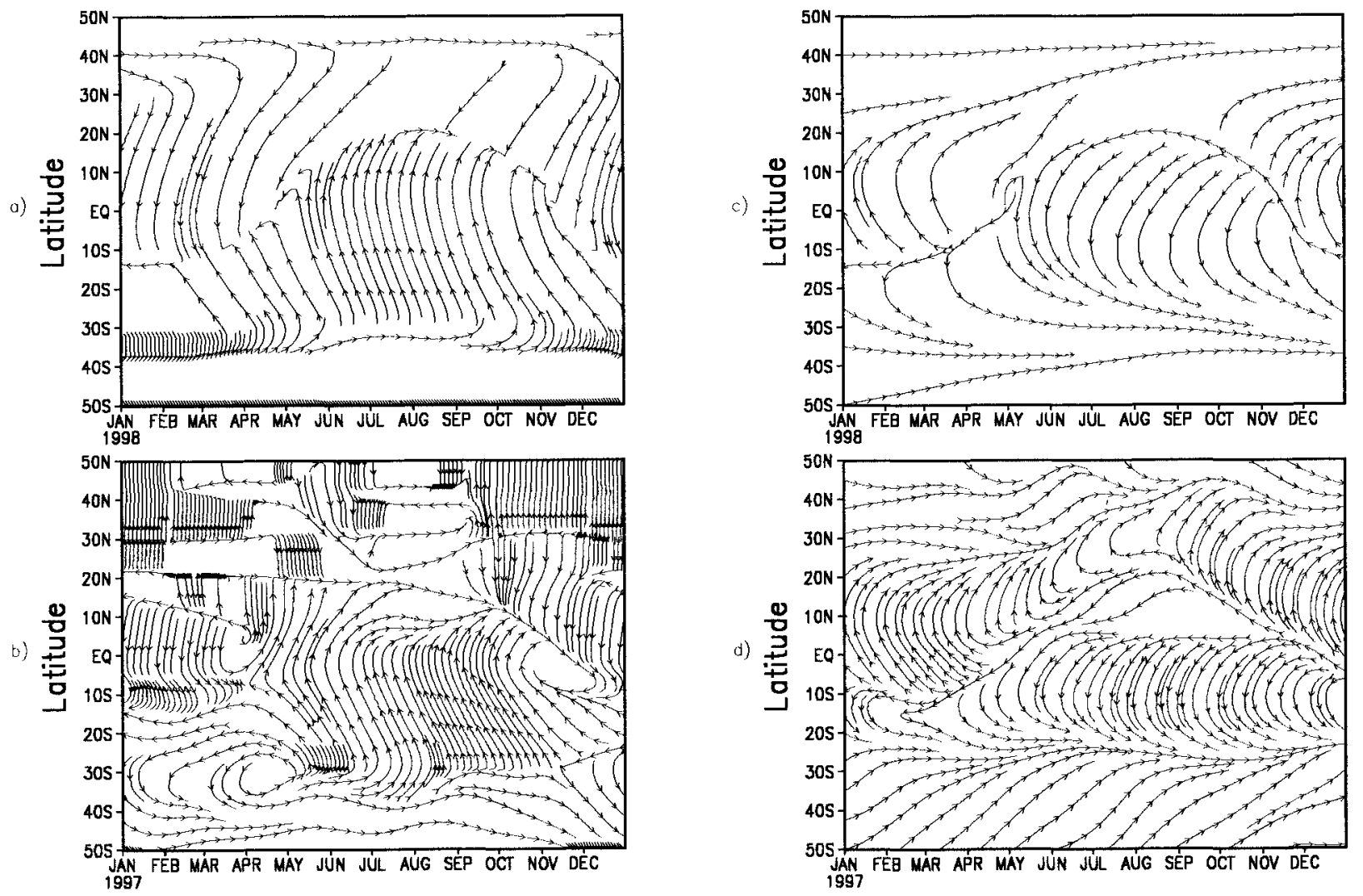

FIG. 8. Annual variation of streamlines: (a) simulated at $925 \mathrm{hPa}$, (b) observed at $925 \mathrm{hPa}$ and $80^{\circ} \mathrm{E}$, (c) simulated at $250 \mathrm{hPa}$, and (d) observed at $250 \mathrm{hPa}$ and $80^{\circ} \mathrm{E}$. The observed values are obtained from the NCEP-NCAR reanalysis data.

cipitation and the vertical velocity at $500 \mathrm{hPa}$ for JJA, respectively. As can be noted, the precipitation is higher along the southern slope of the mountain (Fig. 13a) due mainly to the cumulus convection (Fig. 13c). Also, the maximum of the precipitation is displaced $5^{\circ}$ northward compared to its position when the mountain is removed. As can be seen in Fig. 13b, the rising motion is increased in this region. These results are consistent with those obtained by Hahn and Manabe (1975) and Kuo and Qian (1981, 1982).

Table 2 shows the $U$ - and $V$-indices, the total precipitation, and the convective precipitation, averaged over the equator $-30^{\circ} \mathrm{N}$, for JJA in the cases with and without topography. It can be seen that both the $U$ - and $V$-indices are stronger in the case with topography, suggesting that the monsoonlike circulation is also stronger compared with the case of flat surface. This is agreement with the enhancement of the precipitation when the topography is included in the model. The increase of the total precipitation is due to mainly the increase of the convective precipitation (cumulus convection). The $U$ - and $V$-indices in both the cases with and without topography are strong compared with the observations, suggesting that the model overestimates the strength of monsoon circulation, as mentioned earlier.

Figures $14 \mathrm{a}-\mathrm{c}$ show the latitudinal distribution of the net radiation flux at the land surface and its partitioning into sensible and latent heat fluxes, respectively, for JJA. As can be noted, there is significant differences in the heating fields. The surface net radiation and the sensible and latent fluxes are larger in the southern slope of the mountain compared with the case of flat surface. The increase of heating along the southern foothills from convective heating seems to be due to cumulus convection, as suggested in Fig. 13c and Table 2. When the topography is included, the increase in the latent heating is slightly higher than that in the sensible heat flux. The inclusion of topography causes a decrease in the surface temperature (Fig. 14d) by the lapse-rate effect (Kitch 1997). These results agree, in general, with those obtained from other studies with GCMs (Hahn and Manabe 1975; Kuo and Qian 1981, 1982). However, in the present model the values of the sensible heat flux are smaller than those of the latent heat flux in the tropical region in both the cases with and without topography. Thus, the model results underestimate the role of the sensible heat flux as a heating source, mainly in the case with no mountain.

The topography interacts with the monsoon flow because of both its high elevation and its steep southern slope. To investigate how these factors may affect the simulation of the monsoon circulation, two experiments 

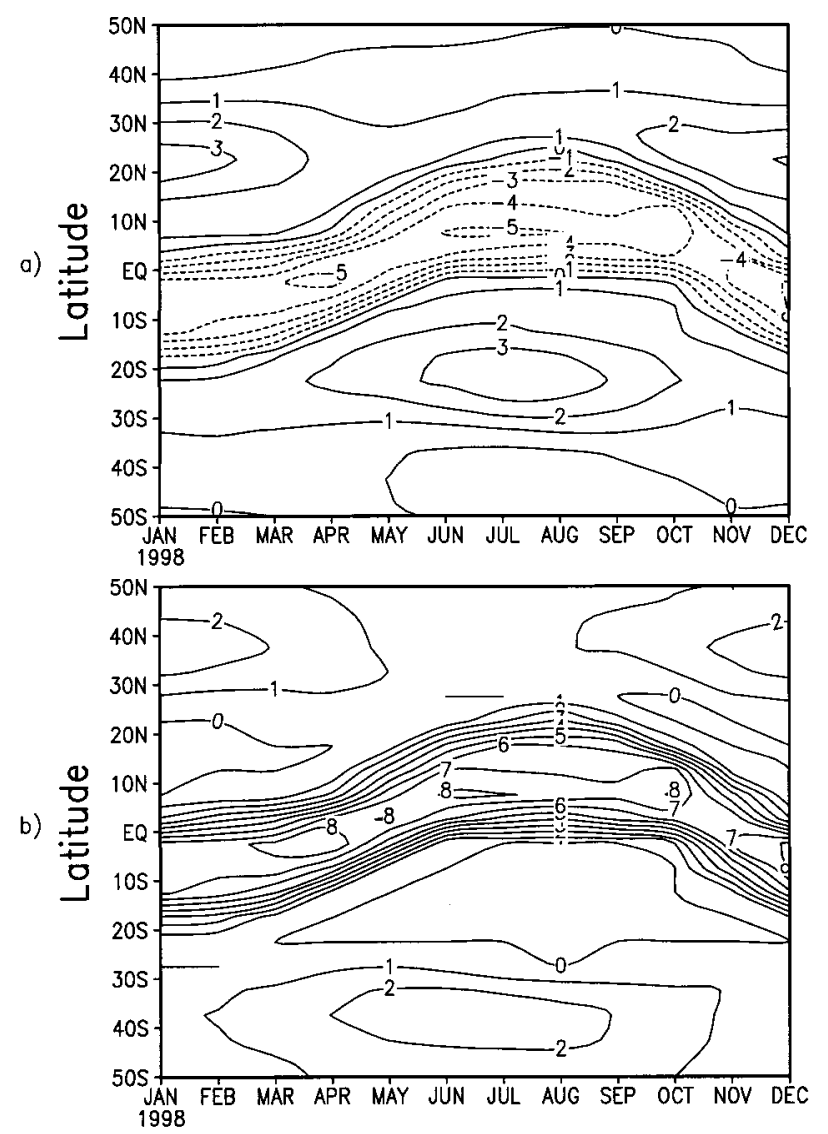

FIG. 9. Annual variation of simulated zonally averaged: (a) vertical velocity $\varpi$ at $500 \mathrm{hPa}\left(10^{-4} \mathrm{hPa} \mathrm{s}^{-1}\right)$; (b) precipitation $\left(\mathrm{mm} \mathrm{day}^{-1}\right)$. Cases with no mountain.

are performed. In the first, we increase the height of the topography without changing the steepness (experiment 1 ); in the other, we increase the height of the topography in the tropical region of the Northern Hemisphere as in the case of the experiment 1 but with a steeper slope (experiment 2). Figure 15 shows the zonally averaged topography used in the experiments 1 and 2 . The original zonally averaged topography used in the ZAGCM (section 3) is also plotted in Fig. 15. The results show that the precipitation in the southern slope of the mountain is higher in experiment 2 compared with experiment 1. The enhancement of precipitation is due to the increase in the rising motion in this region (Figs. 16a,b). The role of gradient of slopes as a key factor of controlling vertical velocities and the rate of condensation of saturated air packets was pointed out by Stephenson et al. (1998). Thus, the results above suggest that the steepness of the slope controls the strength of the monsoonlike circulation in the present model.

\section{The Holocene experiment}

In this section, the ZAGCM is run in order to test the sensitivity of the monsoon circulation for changed
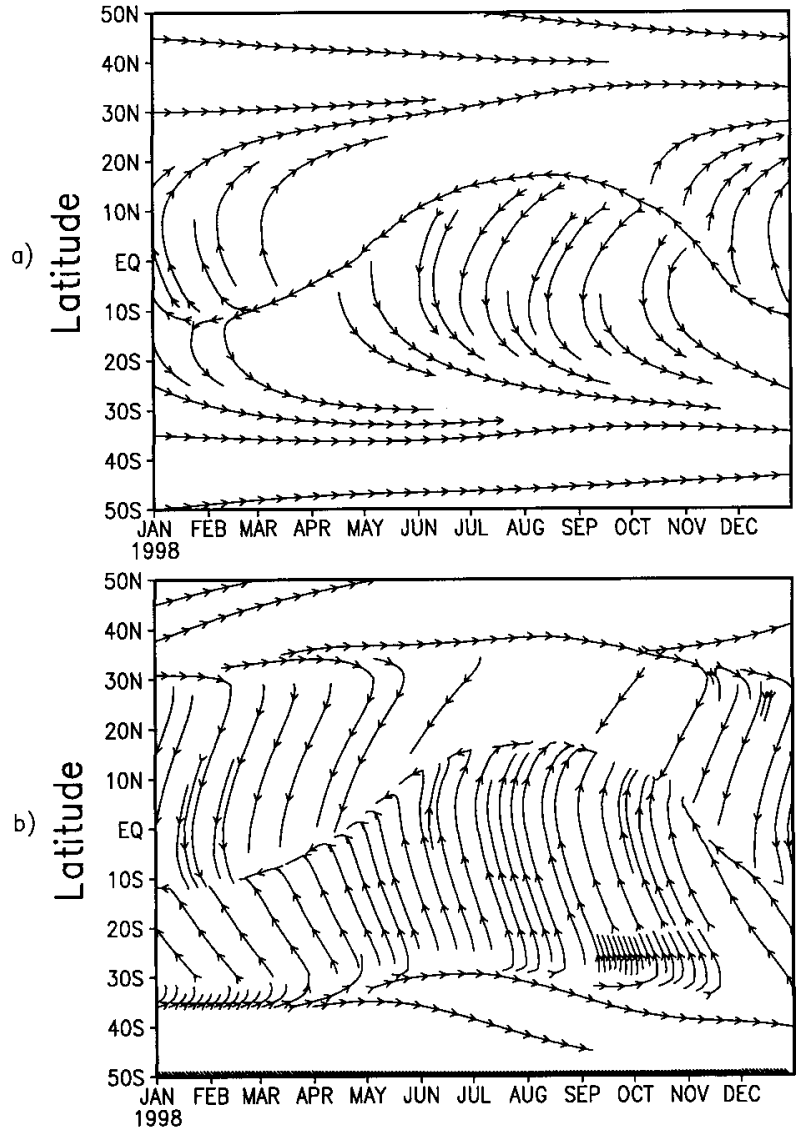

FIG. 10. Annual variation of streamlines simulated by the model without topography: (a) at $250 \mathrm{hPa}$ and (b) at $925 \mathrm{hPa}$.

external conditions. For this purpose we use values of the orbital parameters for $9000 \mathrm{yr}$ BP (Early Holocene). The obliquity was $24.23^{\circ}$ (the modern value is $23.45^{\circ}$ ), perhelion was 30 July (the modern value is 3 January), and eccentricity was 0.0193 (the modern value is 0.0167). The control experiment is the simulation of the present-day climate shown in section 3 (case including topography).

The model results are presented considering the changes in the zonally averaged variables (Holocene minus control experiment). Figure $17 \mathrm{~b}$ shows the departures from the modern control values of the insolation at the top of the atmosphere (Fig. 17a). As can be noted, the larger increase of insolation occurred at high latitudes in the Northern Hemisphere. Although the mean annual insolation was equivalent to its presentday value, the seasonal cycle was enhanced during the Early Holocene, with the Northern Hemisphere receiving more solar radiation in the summer season and less insolation during the winter. The latitudinal distribution of the changes in the insolation at the top of the atmosphere shown in Fig. 17 is similar to that given by de Noblet et al. (1996) for the mid-Holocene minus present-day climate conditions. However, the magnitude 

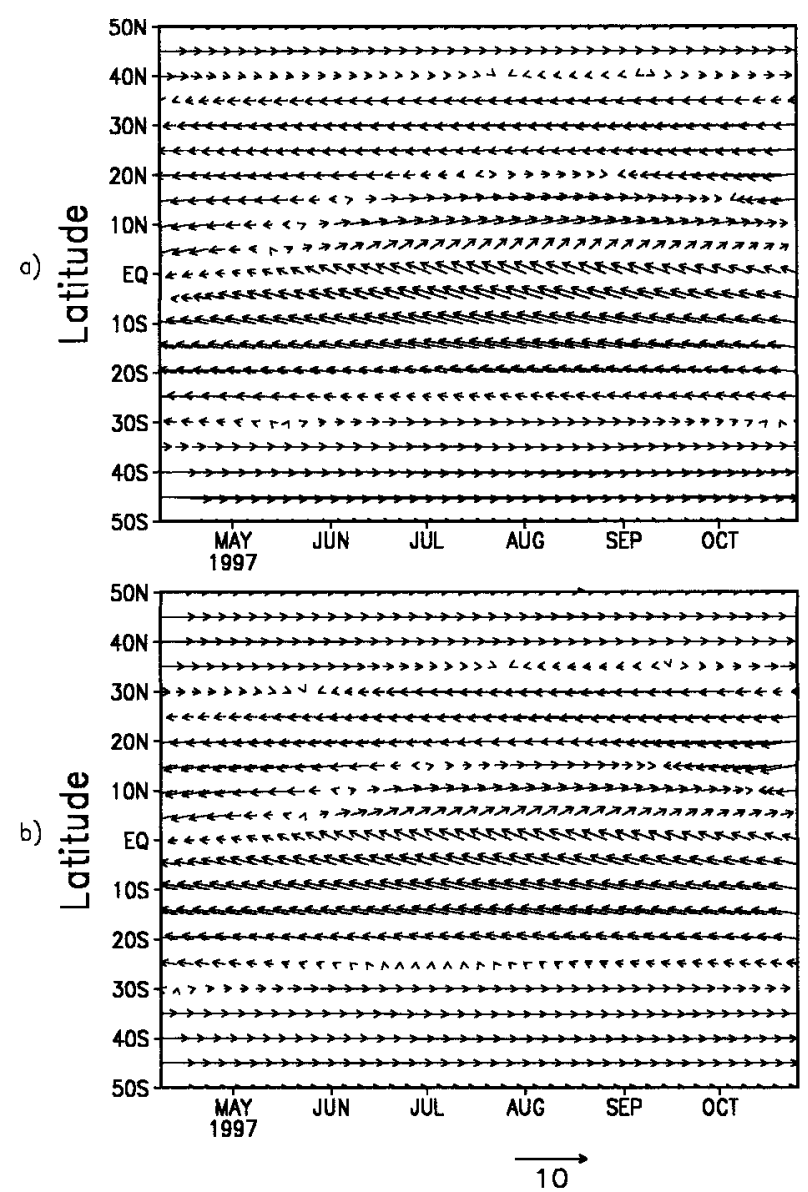

FIG. 11. Annual variation of the horizontal wind vector at $750 \mathrm{hPa}$ simulated by the model: (a) with topography and (b) without topography. Units, $\mathrm{m} \mathrm{s}^{-1}$.

of the changes are larger for the early Holocene minus present-day case.

The increase of the solar radiation at the top of the atmosphere provoked a stronger summer monsoon in the early Holocene. As can be seen in Fig. 18, the surface temperature during the boreal summer was around $0.9 \mathrm{~K}$ higher during the early Holocene than in the modern control experiment. Also, the land surface temperature was around $1.0 \mathrm{~K}$ higher during the boreal summer in the Holocene experiment (not shown). This warming extended from the surface throughout the midatmosphere. The increase of the temperature in the Northern Hemisphere during the summer season provoked an enhancement of the precipitation (around $0.55 \mathrm{~mm} \mathrm{day}^{-1}$ ) in the tropical region of the Northern Hemisphere.

Another Holocene experiment was conducted using the ZAGCM without topography. The changes (Holocene minus modern control experiment) (not shown here) were similar to those shown above. However, the magnitude of the changes was larger when the topography was included into the model.
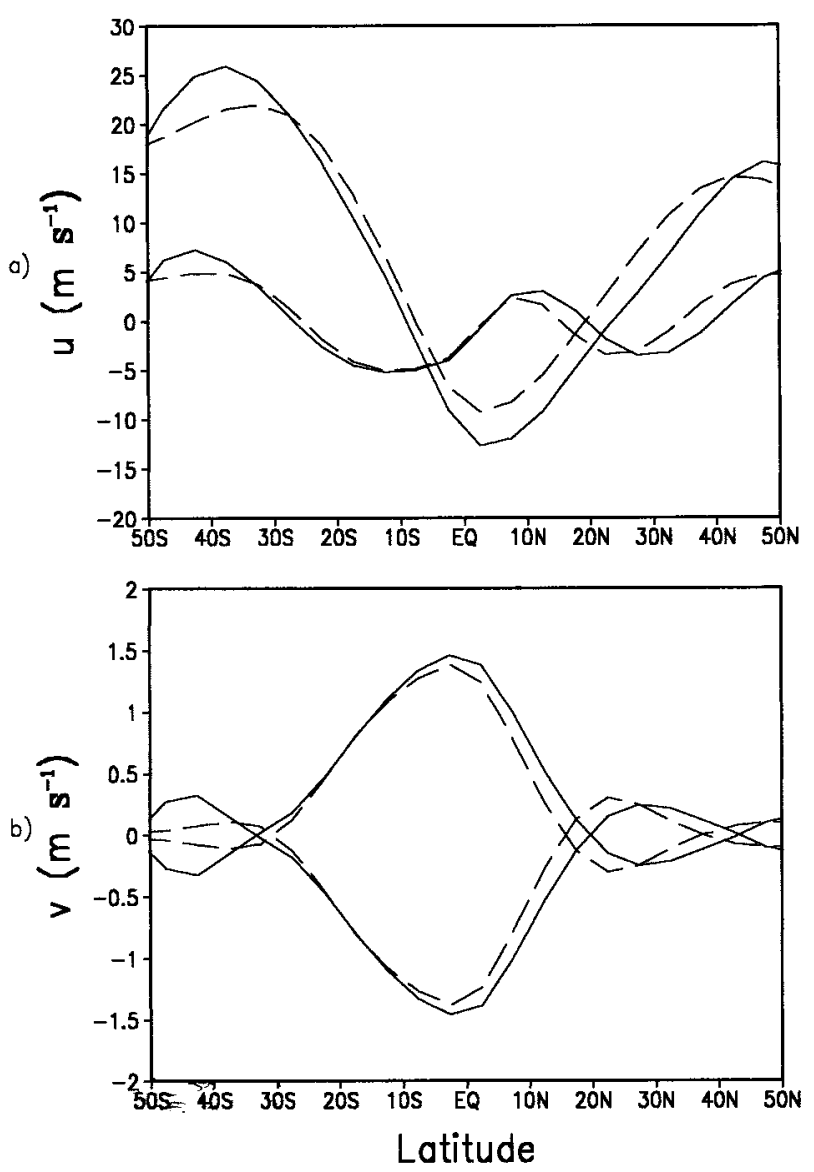

FIG. 12. Three-month means (JJA) of the zonally averaged: (a) zonal winds at $250 \mathrm{hPa}$ and $750 \mathrm{hPa}$, and (b) meridional wind at 250 $\mathrm{hPa}$ and $750 \mathrm{hPa}$ simulated by the model with mountain (full line) and with no mountain (dashed line). Units, $\mathrm{m} \mathrm{s}^{-1}$.

Results from GCMs show an increase of the surface temperature of 2-4 K and an enhancement of precipitation of 1-2 mm day ${ }^{-1}$ (Kutzbach and Gallimore 1988; Mitchell et al. 1988; Kutzbach and Guetter 1986; Mitchell 1977). Again, the model results are consistent with those obtained from more sophisticated models. Also, the simulations are in agreement with observational data (COHMAP Members 1988; Crowley 1983; Street and Grove 1979). Thus, the present ZAGCM is capable of reproducing the sensitivity of monsoonal circulations to changed external conditions such as those of the Early Holocene.

\section{Summary and conclusions}

This paper investigates the feasibility of using a ZAGCM for studying the influence of the topography on the annual cycle. For this purpose, a smoothed zonally averaged topography, which has a form similar to that observed, is included in a two-layer primitive equation global ZAGCM. The model has $5^{\circ}$ lat resolution 

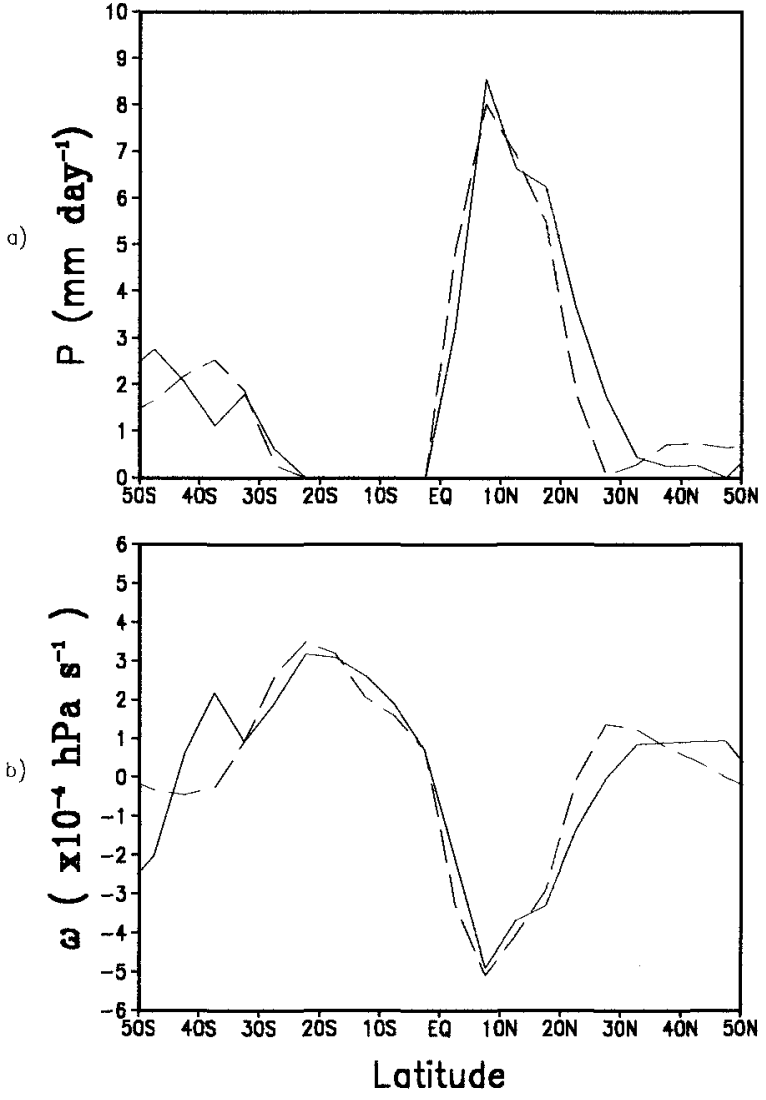

c)

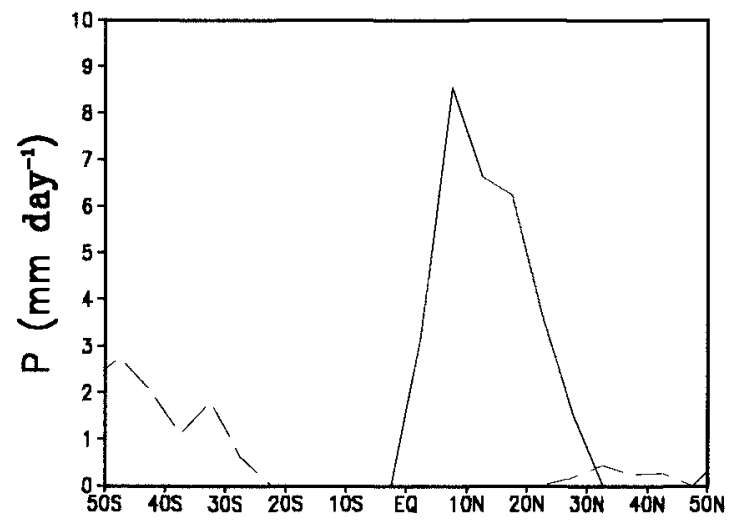

d)

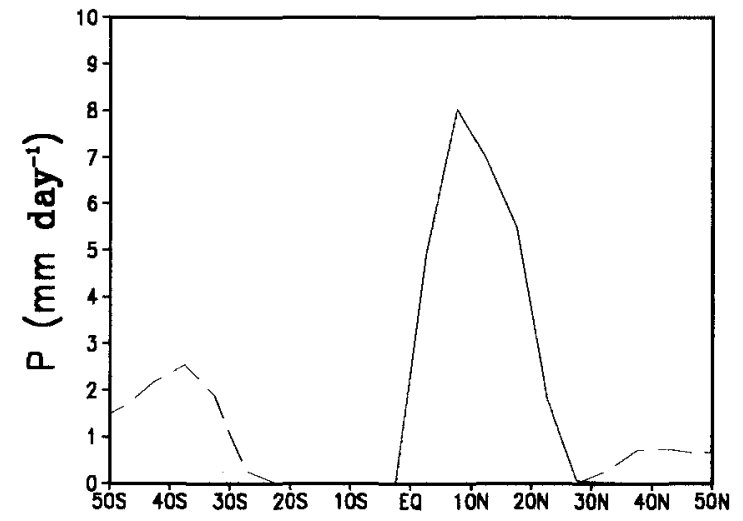

FIG. 13. Three-month means (JJA) of the zonally averaged: (a) total precipitation $\left(\mathrm{mm} \mathrm{day}^{-1}\right)$; (b) vertical velocity $\omega$ at $500 \mathrm{hPa}$ $\left(10^{-4} \mathrm{hPa} \mathrm{s}^{-1}\right)$ simulated by the model with mountain (full line) and with no mountain (dashed line). The zonally averaged convective precipitation (full line) and large-scale precipitation (dashed line) simulated by the model (a) with topography and (b) without topography.

and includes a bulk parameterization of the sensible heat flux and the parameterization of the large-scale precipitation and cumulus convection. The model simulations are compared with the observations obtained from the NCEP-NCAR reanalysis data. The results showed that there is good agreement between the simulated and observed annual cycles.

As monsoon is a response to annual cycle, the capability of the model in capturing some monsoonlike variations is investigated. The role of topography in controlling the monsoon flow and its response to changed external conditions are studied. Since there is

TABLE 2. Simulated and observed values of the zonally averaged $U$-index $\left(U_{250}-U_{750}\right)$, and $V$-index $\left(V_{250}-V_{750}\right)\left(\mathrm{m} \mathrm{s}^{-1}\right)$, total precipitation and convective precipitation $\left(\mathrm{mm} \mathrm{day}^{-1}\right)$. The observations are obtained from the NCEP-NCAR reanalysis data.

\begin{tabular}{lcccc}
\hline \hline & $U$-index & $V$-index & $\mathrm{P}$ & $\mathrm{P}_{\mathrm{c}}$ \\
\hline Run with topography & -6.53 & -0.92 & 5.08 & 5.05 \\
Run without topography & -2.05 & -0.57 & 4.64 & 4.64 \\
Observations & -0.61 & -0.65 & 4.57 & \\
\hline
\end{tabular}

a larger amount of land in the Northern Hemisphere compared to the Southern Hemisphere, which, in turn, contains a larger amount of ocean, the monsoon circulation in the present model is driven by the differential heating between land (to the north) and ocean (to the south). The model includes the effects of sensible and latent (condensation) heat fluxes and topography and thus contains the basic ingredients necessary for the simulation of a monsoon circulation. However, the land-ocean thermal contrast is reduced in the model due to the fact that the different fractions of the earth's surface covered by ocean, land, ice, and snow are considered in each latitude belt. So, in analyzing the results one must keep in mind that they are obtained from a $2 \mathrm{D}$ zonally averaged mechanistic model. The results correspond to zonal means and not to regional features of the actual Asian monsoon. Also, the model includes a smoothed zonally averaged topography, which is different from the Himalayan-Tibetan Plateau. So, the model cannot reproduce exactly all the features observed in the monsoon system.

The results showed that the model even in the absence of topography is able to capture some of the basic fea- 

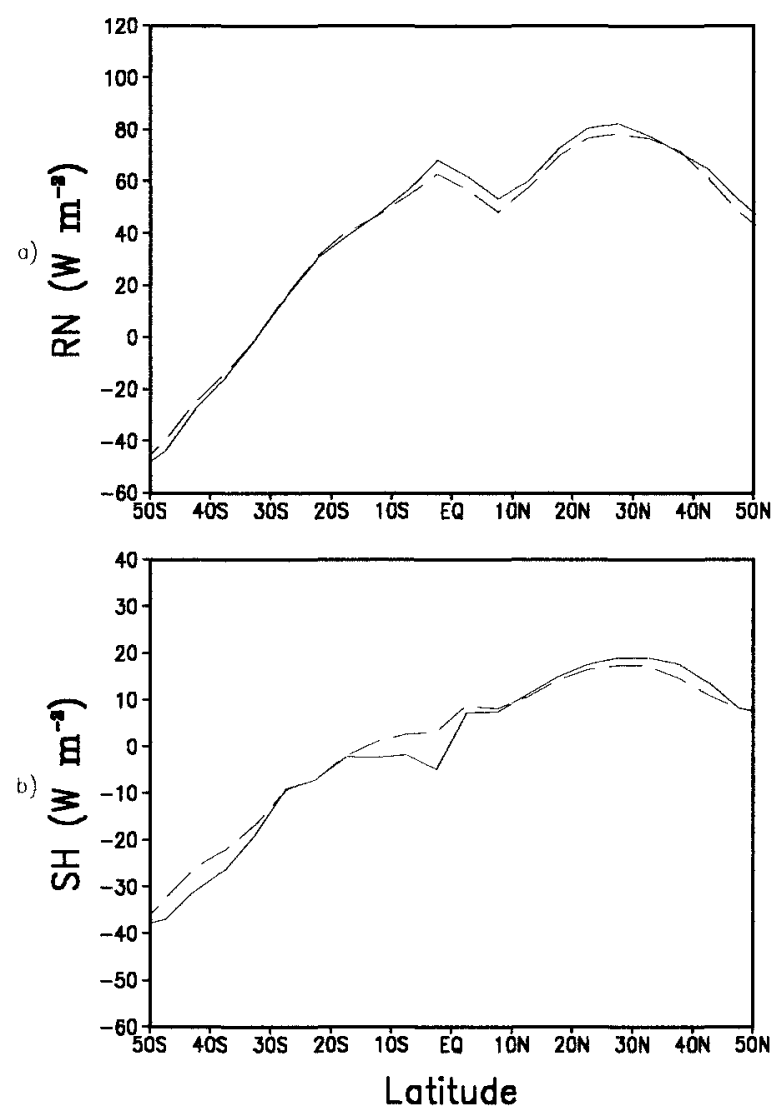
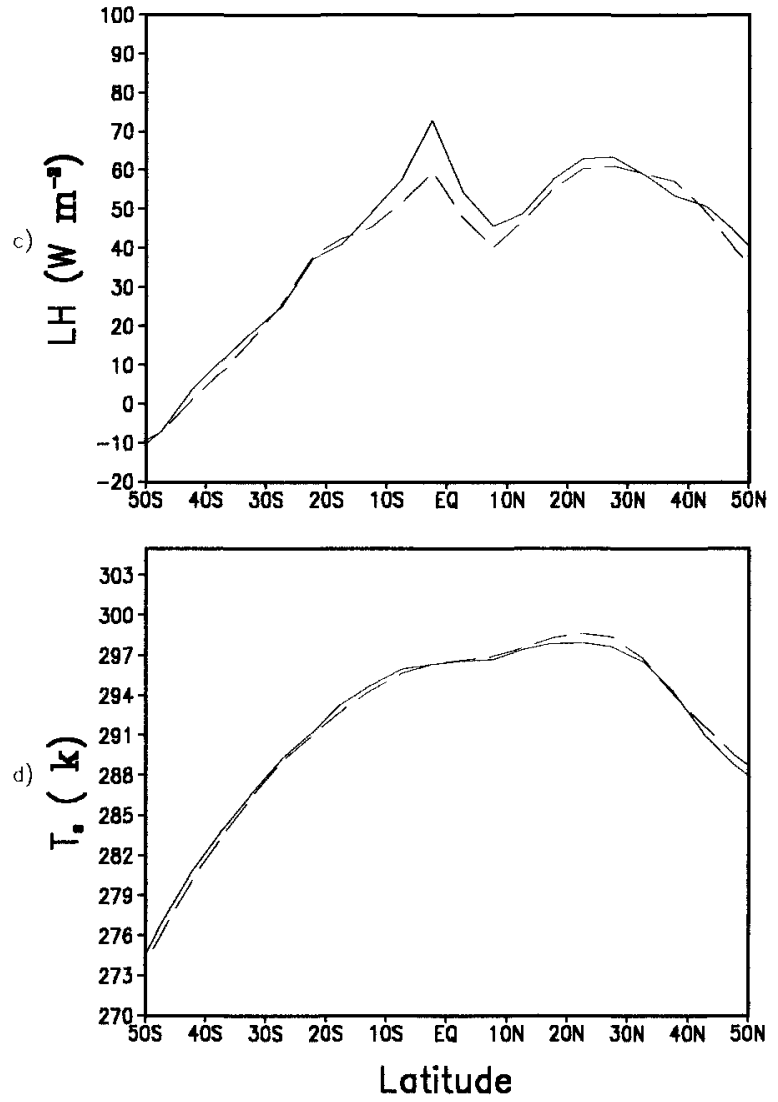

FIG. 14. Three-month means (JJA) of the zonally averaged: (a) surface net radiation, (b) sensible heat flux, (c) latent heat flux, in W m ${ }^{-2}$, and (d) land surface temperature $(\mathrm{K})$. The full line corresponds to the values simulated by the model with mountain and the dashed line refers to those obtained from the model with no mountain.

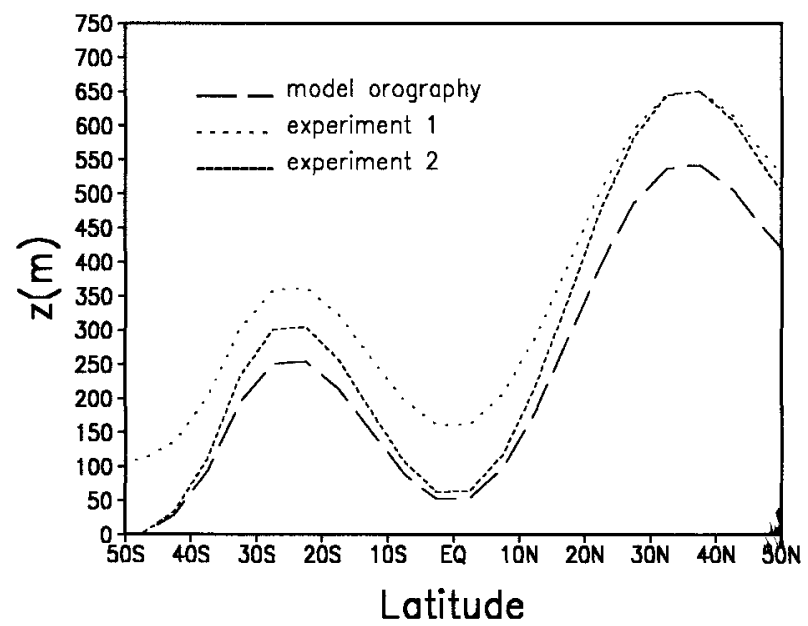

FIG. 15. Zonally averaged topography used in the experiment 1 (increasing the elevation without changing the steepness of slope) and in the experiment 2 (increasing both the elevation and the steepness of the slope). The zonally averaged topography used in the simulation of the annual cycle (Fig. 1) is also plotted for comparison. tures of the monsoon circulation such as the seasonal wind reversal and the easterly jet in the boreal summer. However, in the absence of mountain the monsoon is weak and the subtropical jet does not abruptly jump northward to its summertime position as noted in the observations. In the case with mountain, the model reproduces the rapid northward jump of the westerly jet across the mountain during the circulation onset. Further monsoon circulation penetrates farther north. This shows that the topography has an important role in causing the sudden seasonal wind changes. Evaluation of $U$ and $V$-indices indicated that the model overestimates the strength of the monsoon circulation in both the cases with and without topography. However, the presence of the mountain intensifies the summer monsoon circulation and enhances the precipitation in the region. This increase in precipitation is due mainly to the convective precipitation.

The model was also run in order to investigate the effects of high-elevation orography and its steep southern slope on the monsoonlike circulation. Two experiments were performed: 1 ) increasing the elevation of orography without changing the steepness of the slope, 

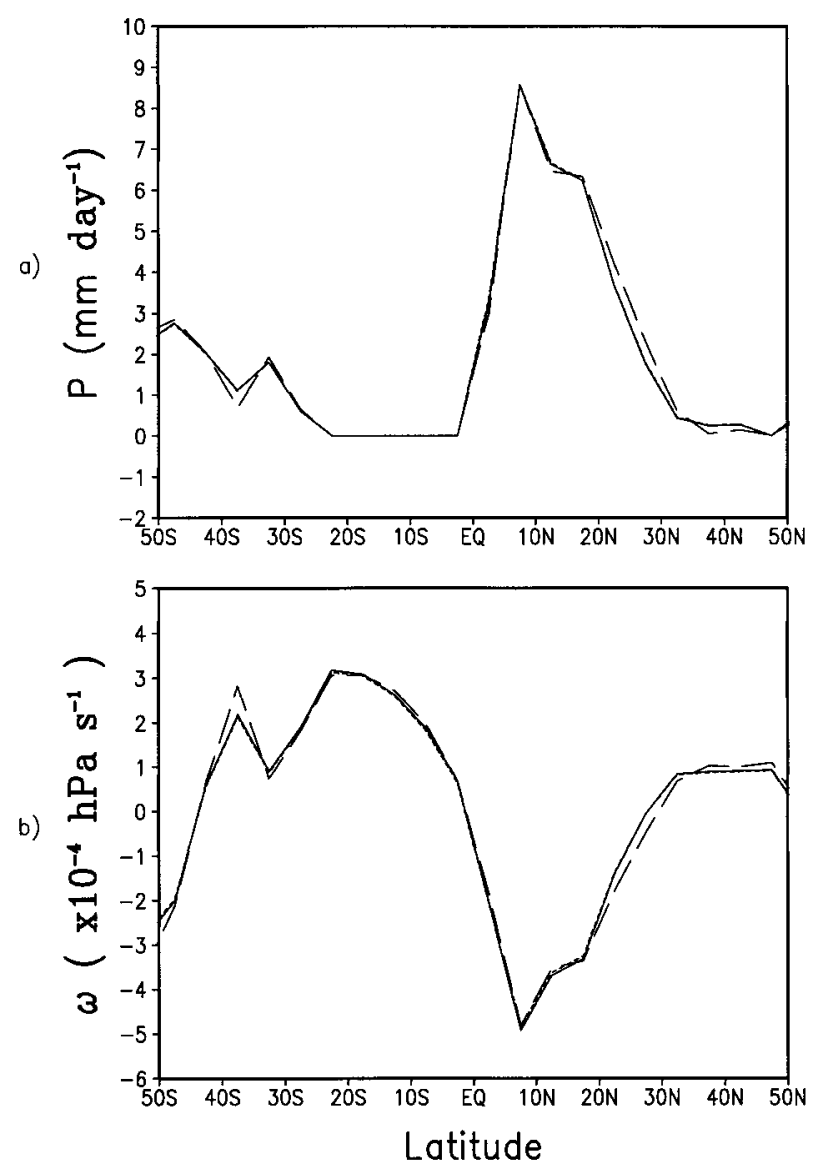

FIG. 16. Simulated zonally averaged: (a) precipitation $\left(\mathrm{mm} \mathrm{day}^{-1}\right)$, and vertical velocity at $500 \mathrm{hPa}\left(10^{-4} \mathrm{hPa} \mathrm{s}^{-1}\right)$ in experiment 1 (full line) and experiment 2 (dashed line).

and 2) increasing both the elevation and the steepness of the slope. The results showed that the steeper southern slope causes an increase in the rising motion and, consequently, an enhancement of the precipitation. Thus, the steepness of the southern slope seems to control the strength of monsoon flow in the model.

To investigate the ability of the ZAGCM to test the sensitivity of the monsoonlike circulation to changed external conditions, the model was run using the solar radiation conditions during the Early Holocene (9000 yr BP). The Holocene experiment showed that the precipitation and circulation intensified, which agrees with paleoclimatic evidence. It can be concluded that despite the limitations of the present simple model, it was able to capture the essential mechanisms responsible for past climatic change.

In summary, the present model is not only able to simulate a monsoonlike circulation, but it is also capable of reproducing its sensitivity to changed external conditions. In general, the model results are consistent with those obtained from sophisticated and complex threedimensional GCMs and are in agreement with the ob-
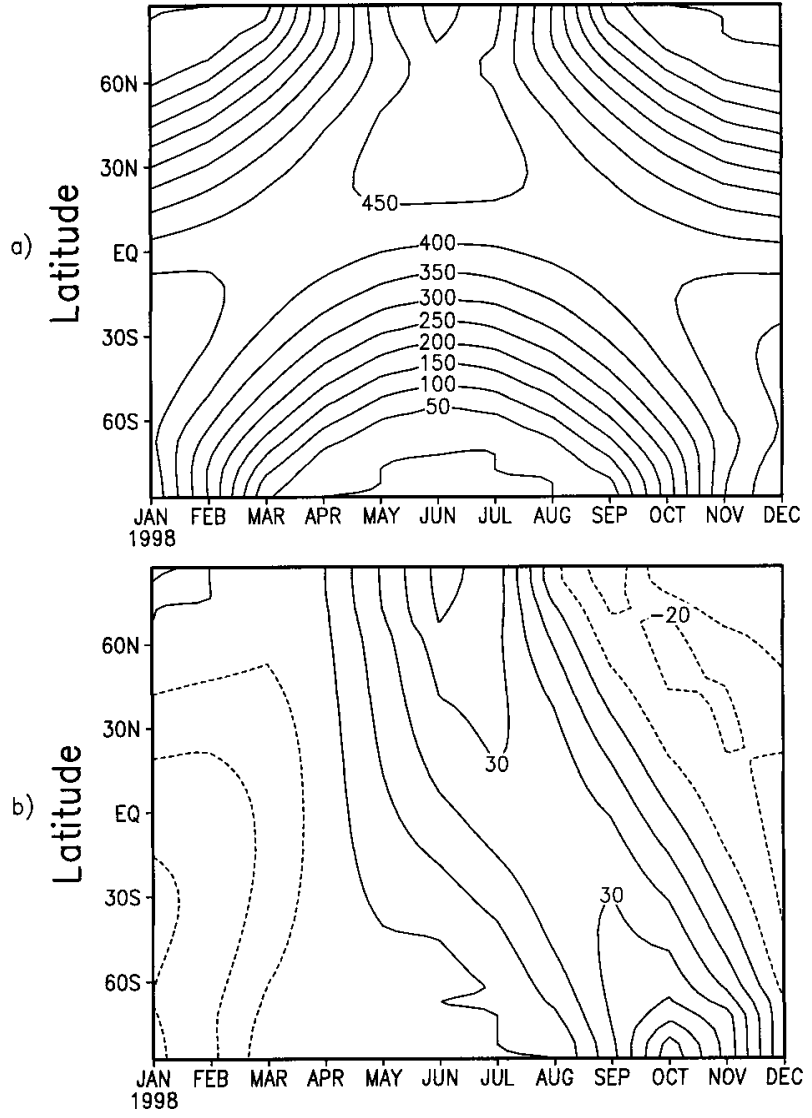

FIG. 17. Insolation at the top of the atmosphere: (a) modern control values, and (b) departures (Holocene minus control experiment) from the modern control values. Units, $\mathrm{W} \mathrm{m}^{-2}$.

servations, showing that the ZAGCM is a good complement to GCMs studies.

Acknowledgments. Thanks are due to the official reviewers for many useful suggestions.

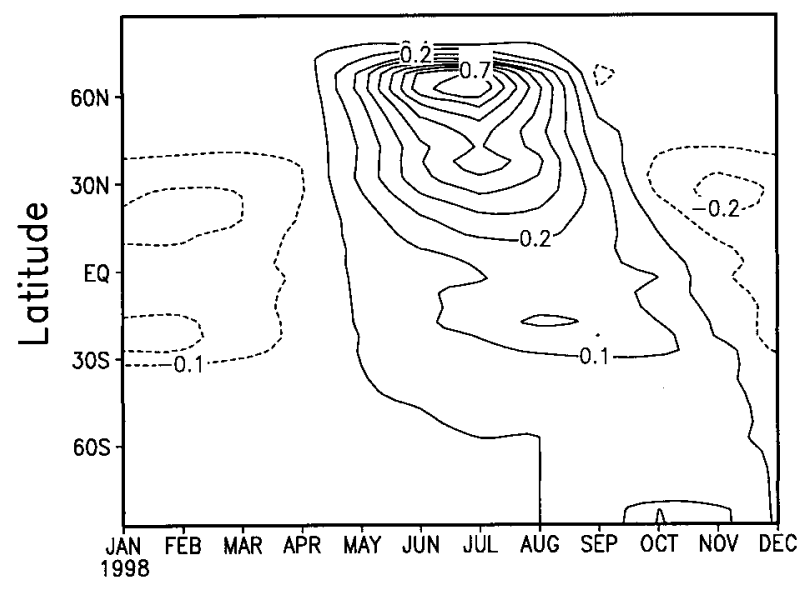

FIG. 18. Changes in the surface temperature (K). The Holocene experiment minus control experiment. 


\section{REFERENCES}

Berger, A., 1978: Long-term variations of daily insolation and quaternary climatic changes. J. Atmos. Sci., 35, 2362-2367.

Brown, J. A., and K. A. Campana, 1978: An economical time-differencing system for numerical weather prediction. Mon. Wea. Rev., 106, 1125-1136.

COHMAP Members, 1988: Climatic changes of the last 18000 years: Observations and model simulations. Science, 241, 1043-1052.

Crowley, T. J., 1983: The geological record of climate change. Rev. Geophys. Space Phys., 21, 828-877.

Das, P. K., and H. S. Bedi, 1981: A numerical model of the monsoon trough. Monsoon Dynamics, J. Lighthill and R. P. Pearce, Eds., Cambridge University Press, 351-363.

de Noblet, N., P. Bracount, S. Joussaume, and V. Masson, 1996: Sensitivity of simulated Asian and African summer monsoons to orbitally induced variations in insolation 126,115 , and $6 \mathrm{~K}$ BP. Climate Dyn., 12, 589-603.

Fein, J., and P. L. Stephens, 1987: Monsoons. Wiley InterScience, $632 \mathrm{pp}$.

Franchito, S. H., and V. B. Rao, 1992: Climatic change due to land surface alterations. Climatic Change, 22, 1-34.

— , and - 1995: On the simulation of sea surface temperature with a zonally averaged model. Global Atmos. Ocean Syst., 3, $35-53$.

— - — , and R. R. Silva, 1998: A parameterization of radiative fluxes suitable for use in a statistical-dynamical model. Meteor. Atmos. Phys., 69, 23-38.

Gadgil, S., S. Sajani, and participating AMIP Modelling Groups, 1998: Monsoon precipitation in AMIP runs. WMO/TD-NO. 837, $88 \mathrm{pp}$.

Gutman, G., G. Ohring, and J. H. Joseph, 1984: Interaction between the geobotanic state and climate: A suggested approach and a test with a zonal model. J. Atmos. Sci., 41, 2663-2678.

Hahn, D. G., and S. Manabe, 1975: The role of mountains in the South Asian monsoonal circulation. J. Atmos. Sci., 32, 15151541.

Haltiner, G. J., and R. T. Williams, 1980: Numerical Prediction and Dynamical Meteorology. 2d ed. John Wiley and Sons, 477 pp.

Held, I. M., and M. J. Suarez, 1978: A two-level primitive equation model designed for climatic sensitivity experiments. J. Atmos. Sci., 35, 206-229.

Kalnay, E., and Coauthors, 1996: The NCEP/NCAR 40-Year Reanalysis Project. Bull. Amer. Meteor. Soc., 77, 437-471.

Kitch, A., 1997: Mountain uplift and surface temperature changes. Geophys. Res. Lett., 24, 185-188.

Krishnamurti, T. N., 1987: Monsoon models. Monsoons, J. S. Fein and P. L. Stephens, Eds., John Wiley and Sons, 467-522.

Kuo, H. L., and Y.-F., Qian, 1981: Influence of the Tibetean Plateau on cumulative and diurnal changes of weather and climate in summer. Mon. Wea. Rev., 109, 2337-2356.

- , and - 1982: Numerical simulation of the development of mean monsoonal circulation in July. Mon. Wea. Rev., 110, 18791897.

Kutzbach, J. E., and P. J. Guetter, 1986: The influence of changing orbital parameters and surface boundary conditions on climate simulations for the past 9000 years. J. Atmos. Sci., 43, 17261759.

_ - and R. G. Gallimore, 1988: Sensitivity of a coupled atmosphere/ mixed layer ocean model to changes in orbital forcing at 9000 years BP. J. Geophys. Res, 93, 803-821.

Lau, K.-M., and S. Yang, 1996: Seasonal variation, abrupt transition, and intraseasonal variability associated with the Asian summer monsoon in the GLA GCM. J. Climate, 9, 965-985.

— J. H. Kim, and Y. Sud, 1996: Intercomparison of hydrologic processes in AMIP GCMs. Bull. Amer. Meteor. Soc., 77, 22092227.

Meehl, G. A., 1992: Effect of tropical topography on global climate. Annual Review of Earth and Planetary Sciences, G. W. Whetherill, A. L. Albee, and K. C. Burke, Eds., Vol. 20, Annual Reviews, Inc., 85-112.

Mitchell, J. F. B., 1977: The effect on climate of changing the Earth's orbital parameters: Two summer integrations with fixed sea-surface temperature. Met 020 Tech. Note 11/100, 18 pp. [Available from The Meteorological Office, Bracknell, Berkshire RG12 252, United Kingdom.]

- N. S. Grahame, and K. H. Needham, 1988: Climate simulations for 9000 years before present: Seasonal variations and the effect of the Laurentide ice sheet. J. Geophys. Res., 93, 8283-8303.

Murakami, T., 1987: Orography and monsoons. Monsoons, J. S. Fein and P. L. Stephens, Eds., John Wiley and Sons, 331-364.

— , R. V. Godbole, and R. R. Kelkar, 1970: Numerical simulation of the monsoon along $80^{\circ}$ E. Proc. Conf. on the Summer Monsoon of Southeast Asia, Norfolk, VA, Navy Weather Research Facility, $39-51$.

Rao, V. B., and S. H. Franchito, 1993: Response of a simple model to the sea surface temperature anomalies. Ann. Geophys., 11, 846-856.

Riehl, H., 1979: Climate and Weather in the Tropics. Academic Press, $611 \mathrm{pp}$.

Saltzman, B., 1968: Steady state solutions for the axially-symmetric climate variables. Pure Appl. Geophys., 69, 237-259.

— axially-symmetric component of the Earth's macroclimate. $J$. Geophys. Res., 76, 1498-1524.

— averaged macroclimate. J. Geophys. Res., 77, 3936-3945.

Stephenson, D. B., F. Chauvin, and J.-F. Royer, 1998: Simulation of the Asian summer monsoon and its dependence on model horizontal resolution. J. Meteor. Soc. Japan, 76, 237-265.

Street, F. A., and A. T. Grove, 1979: Global maps of lake-level fluctuations since 30000 years BP. Quat. Res., 12, 83-118.

Tang, C.-M., 1976: The influence of meridional sloping topography on baroclinic instability and its implications for macroclimate. J. Atmos. Sci., 33, 592-601.

Varejão Silva, M. A., S. H. Franchito, and V. B. Rao, 1998: A coupled biosphere-atmosphere climate model suitable for studies of climatic change due to land surface alterations. J. Climate, 11, 1749-1767.

Webster, P. J., 1983: Mechanisms of monsoon low-frequency variability: Surface hydrological effects. J. Atmos. Sci., 40, 21102124.

_ and K. M. Lau, 1977: A simple ocean-atmosphere climate model: Basic model and a simple experiment. J. Atmos. Sci., 34, 1063-1084.

— , and L. C. Chou, 1980: Seasonal structure of a simple monsoon system. J. Atmos. Sci., 37, 354-367.

systems. Quart. J. Roy. Meteor. Soc., 118, 877-926.

Yin, M. T., 1949: A synoptic-aerologic study of the onset of the summer monsoon over India and Burma. J. Meteor., 6, 393400 . 